Research Library Issues

RLI 295

2018
/ ASSOCIATION LIBRARIES 


\section{In This Issue}

Demographic Trends in the ARL Library Professional Population: An Overview $\quad 3$

Delayed Retirements and the Youth Movement among ARL Library Professionals 6

Retirements Delayed, Not Eliminated

Youth Movement Starts Now?

A Case of Very Delayed Retirement?

A Delayed but Significant Youth Movement

Endnotes

Hiring and Staffing Trends in ARL Libraries

Continued Rise of Nontraditional Professional Jobs

Present and Near-Term Demand for Job Categories

The Special Case of Library Leadership

New Hires and the MLS Degree

Professional Hiring in the Context of Overall Library Staffing

Endnotes

Selected Demographic Trends in the ARL Professional Population

Canadian Salary Advantage

Historically Underrepresented Groups

Female and Male ARL Professionals

Millennials

Endnotes 


\section{Demographic Trends in the ARL Library Professional Population: An Overview}

Steven Mandeville-Gamble, University Librarian, University of California, Riverside

In the following articles, Stanley Wilder explores a series of trends shaping the professional population of Association of Research Libraries (ARL) member institutions. For 30 years, research libraries have been talking about the "greying of the profession" and the inevitable mass turnover in professional staff that was sure to result from this demographic trend. But year after year, that mass retirement had not played out. By digging into the ARL Salary Survey data, Wilder makes significant observations of how the demographic trends are unfolding and how geopolitical and economic forces outside of the boundaries of the profession itself, namely the economic collapse of 2008-2009, encouraged many library professionals to delay retirement. Wilder's research shows that this mass trend towards delayed retirements significantly distorted the distribution of professionals by age, away from a natural distribution curve to one that was highly shifted towards the higher end of the age spectrum. But the logical end point of that distorted distribution curve has finally been reached, and the mass wave of retirements is even more momentous as a result.

Simultaneously, Wilder's research underscores a harsh reality: research libraries have dramatically reduced the overall size of their staff since the beginning of the Great Recession, which has resulted in far fewer positions available to younger colleagues than has been true historically. So while the waves of mass retirement are happening, this is a moment in time when there are far fewer positions available overall than even a decade ago.

This is particularly troubling for a profession that has been discussing the need for dramatic demographic shifts to ensure that the profession reflects the demographics of its larger community. As Wilder's research makes clear, the profession as a whole and the members of 
ARL in particular have barely moved the needle in terms of hiring and retaining members of underrepresented groups.

While there are some signs of improvement in terms of the salaries of members of underrepresented communities now being in line with those of their colleagues of Northern European ancestry both in the United States and Canada, Wilder makes a compelling case that overall the percentage of underrepresented groups in the profession has improved only a scant number of percentage points in the last three decades. And though there are regional variations, such as research libraries in the Western United States and Canada having a significantly higher percentage of members of underrepresented communities than their peer institutions in other regions of the

Wilder's articles serve as a powerful illumination of the demographic shifts taking place in the research library profession...while also serving as a call to action for leaders in the profession by identifying where they should put their energies in addressing the emerging needs of their organizations and addressing disparities in the profession as a whole.

US and Canada, those percentages are still far below the levels of the population of the Western regions of both countries.

Wilder's articles serve as a powerful illumination of the demographic shifts taking place in the research library profession, where progress has been made towards realizing long-standing goals vis-à-vis diversity and inclusion, the closing of the income gap across racial and ethnic lines, and the lopsided nature of the age distribution curve...and the inevitable major correction that has already begun as older librarians reach a natural age limit on how long they can continue working. The insights that Wilder's research shines on these and other demographic realities both serves to elucidate these complex demographic trends while also serving as a call to action for leaders in the profession by identifying where they should put their energies in addressing the 
emerging needs of their organizations and addressing disparities in the profession as a whole.

(c) 2018 Steven Mandeville-Gamble

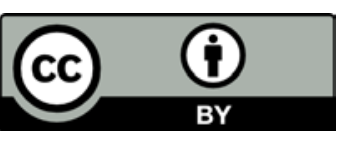

This article is licensed under a Creative Commons Attribution 4.0 International License. To view a copy of this license, visit https:// creativecommons.org/licenses/by/4.0/.

To cite this article: Steven Mandeville-Gamble. "Demographic Trends in the ARL Library Professional Population: An Overview.” Research Library Issues, no. 295 (2018): 3-5. https://doi.org/10.29242/rli.295.1. 


\section{Delayed Retirements and the Youth Movement among ARL Library Professionals}

Stanley Wilder, Dean of Libraries, Louisiana State University

Library professionals have never been older.

The average age of library professionals in the most recent Association of Research Libraries (ARL) demographic data (2015) was 49, making this the oldest population in the 29 -year history of this data series. ${ }^{1}$ More to the point, the 2015 ARL population had an unusual skew towards the oldest age cohorts: $24 \%$ were aged 60 and over, up from just 9\% in 1986.

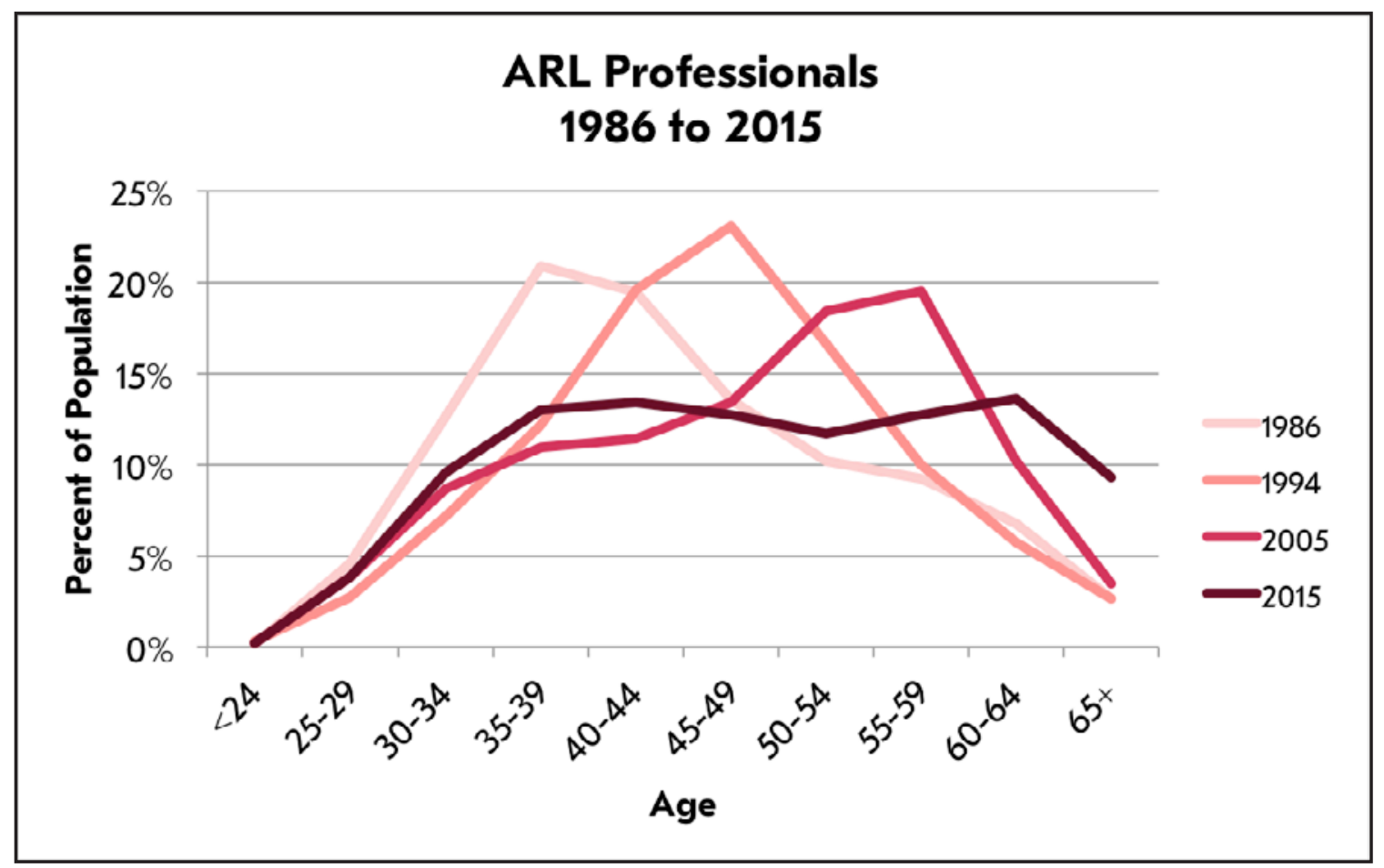

Figure 1

Over 9\% of ARL professionals in 2015 were aged 65 and over, nearly three times the number in the population just 10 years earlier.

The aging of librarian populations in the US is a long-standing phenomenon, so much so that we might be tempted to conclude that 
the 2015 population is just more of the same. ${ }^{2}$ But the 2015 data are surprising, for the simple reason that a professional population cannot age indefinitely. If the profession is to avoid outright extinction, it must at some point fill the vacancies created by retirements, refreshing its ranks with younger individuals.

This is exactly what should have happened in ARL libraries between 2010 and 2015, according to the projections produced from the 2000 data set. ${ }^{3}$ Those projections described a population with an apex cohort (the largest age group within the population) that would age rapidly through 2010, when it would reach the 55-59 age cohort.

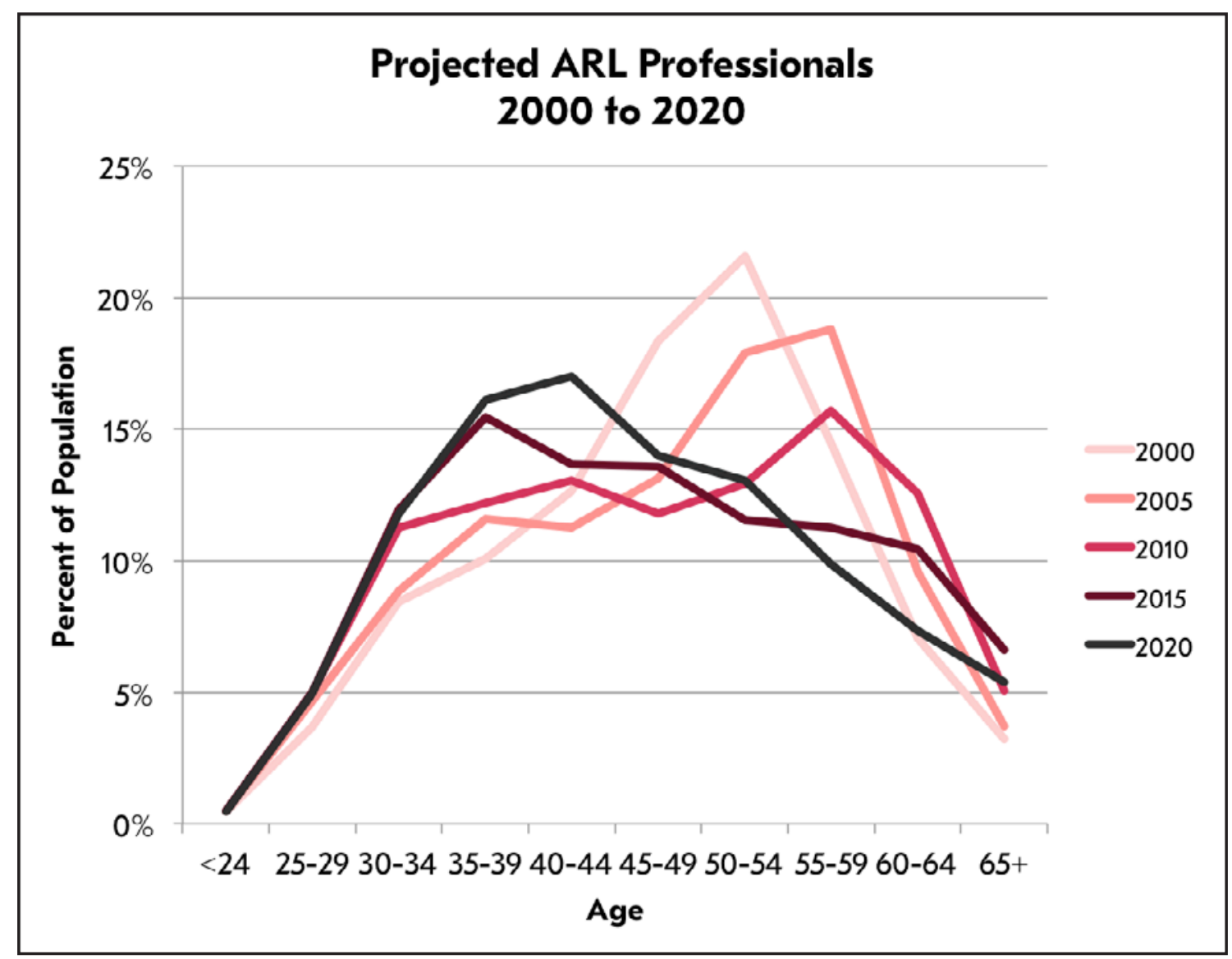

Figure 2

The projections predicted, however, that the five years beginning in 2010 were to be an inflection point. Already by 2015, the apex would shift to the 35-39 cohort, the beginning of a youth movement that 
would carry on through 2020. In that glorious year, a majority of the population would be aged 50 and under for the first time since 2000 . At that point, the profession's age profile would resemble the actual 1986 population of ARL professionals, the first and also the youngest population in the data series.

What those projections failed to anticipate was that 2010, far from marking a changing of the generational guard, would instead be the beginning of a sudden and dramatic turn towards delayed retirement. The retirement-prone 65+ age cohort, which had been stable at about $3 \%$ of the population since 1986, jumped to $5 \%$ in 2010 , and then to over $9 \%$ in 2015. Delayed retirement is also evident in the librarian population tracked in the US Current Population Survey (CPS), where the $65+$ cohort more than tripled between 2005 and 2015 to almost 11\%.

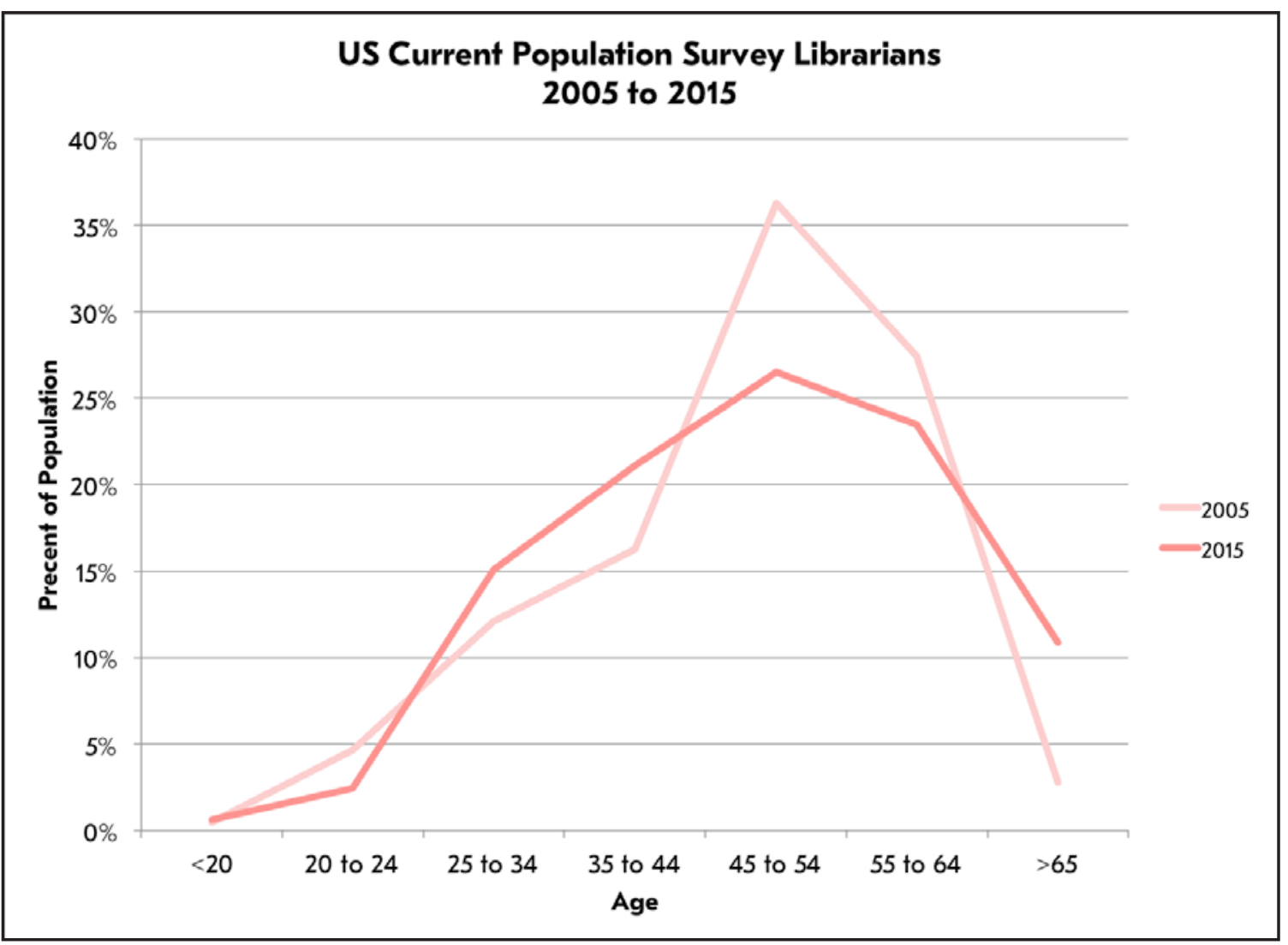

Figure 3 
One explanation for the disconnect between the actual and projected retirement behavior among ARL professionals is the 2008 recession, an event that disrupted everyone's idea of economic normalcy. In the US economy as a whole, the recession resulted in the loss of almost nine million jobs, and doubled the unemployment rate. ${ }^{4}$ In the process, the recession had a devastating impact on pension savings, and on perceptions of retirement preparedness. ${ }^{5}$ Coming as it did at a time of broad-based disinvestment in public infrastructure of all kinds, budget cuts to higher education were common, with some states reducing support by as much as 55\% between 2008 and $2016 .{ }^{6}$ In such a climate, it seems reasonable that more individuals would consider their reduced wealth and the general economic uncertainty around them, and delay their retirements as a result. ${ }^{7}$

Alternatively, it could be that the 2000 projections simply missed a delayed retirement phenomenon that would have happened even without a recession. Labor force projections from the Bureau of Labor Statistics (BLS) have predicted rising numbers of individuals throughout the older age cohorts since at least 2000, a function of aging baby boomers. ${ }^{8}$ A 2012 BLS study acknowledged the recession, but discounted its impact. ${ }^{9}$ The notion that delayed retirement might be nothing more than a reflection of general demographic dynamics can be found in the CPS data noted above. Librarians in that data are just one of hundreds of professions in the US, and that larger population also shows signs of a recent trend towards delayed retirement. Basic population ...the 2015 ARL [professional] population had an unusual skew towards the oldest age cohorts: $24 \%$ were aged 60 and over, up from just $9 \%$ in 1986. demographics must account for some of the delayed retirement among ARL professionals, and it may account for most of it.

It is worth noting that while Canadian ARL professionals can also be said to be delaying retirement, they do so at half the rate of their 
colleagues in the US. The portion of the Canadian ARL professional population that is $65+$ rose from just $0.4 \%$ in 2005 to $4.7 \%$ in 2015 .

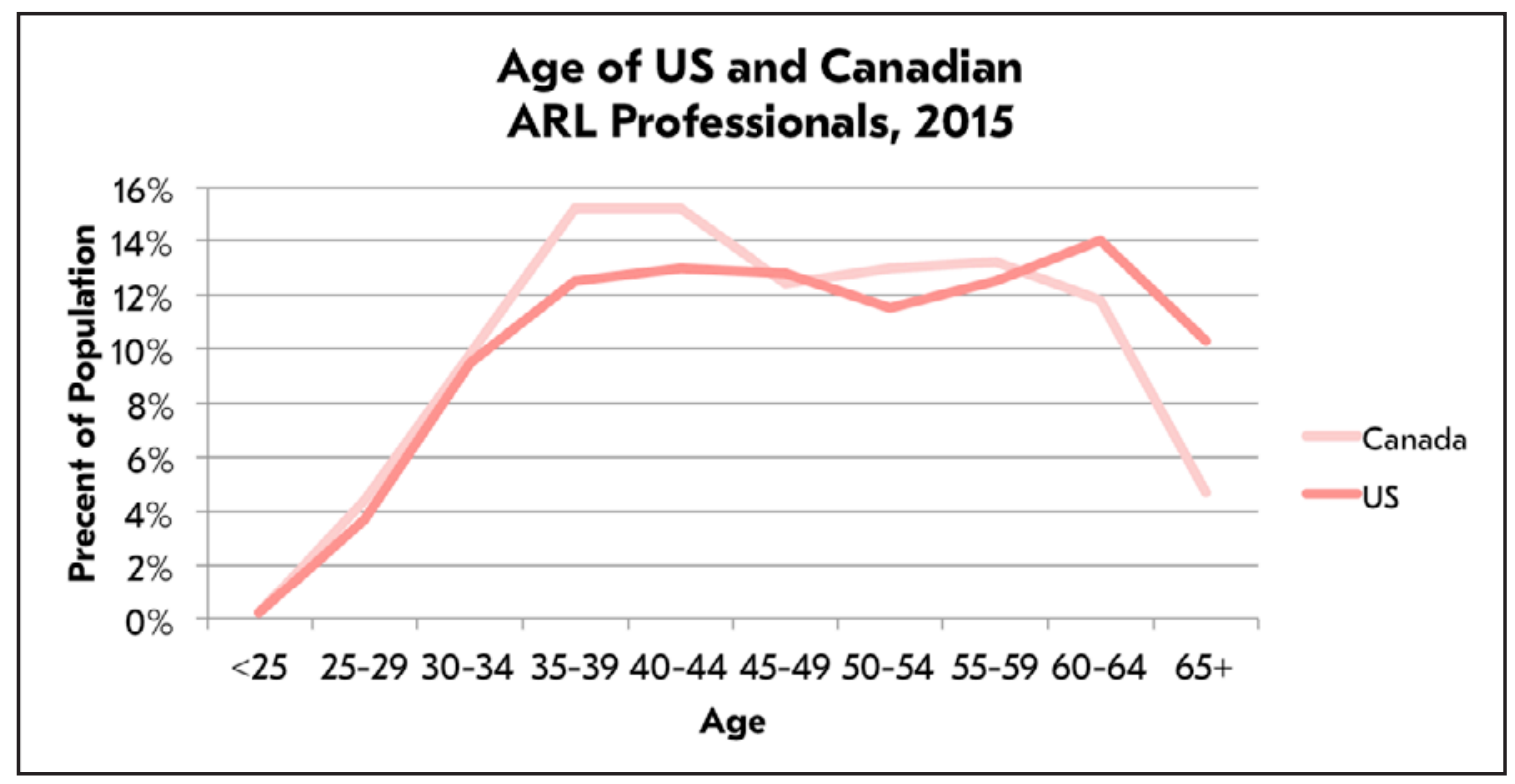

Figure 4

\section{Retirements Delayed, Not Eliminated}

Whatever the cause or causes of ARL's delayed retirements, there is no evidence that people are foregoing retirement altogether. Retirement is a deeply rooted, cultural, even biological phenomenon, one that is affected but not determined by changing economic conditions or legal provisions..$^{10}$ Among ARL professionals, a paltry $1.5 \%$ continued to work at 70 and beyond, and while that represents an uptick relative to 2005 , this is still a very small number of individuals.

With eventual retirement a virtual certainty, what can we expect in the five years between 2015 and 2020? It is not possible to derive a formal retirement rate from the ARL demographic data, but given that net changes to the size of cohorts are fairly consistent from one data set to the next, rough estimates are possible. For example: in any given year, the percentage of the population aged 60-64 drops by about half relative to the $65+$ cohort five years later. ${ }^{11}$ Applying this calculation to the 2015 population, we would expect that by 2020,689 vacancies will arise from the 60-64 cohort alone. 
Another approach is necessary to estimate the number of individuals from the 2015 population aged $65+$ who will leave the population by 2020 . To calculate this estimate, I subtracted the percentage of individuals 70 and older who might remain in the population (1.5\%) from the percentage in the $201565+$ cohort (9.3\%). This reduces the percentage of the 2015 population aged $65+$ that can be expected to leave by 2020 to $7.8 \%$, the equivalent of approximately 790 vacancies. Combining these two estimates, 689 vacancies from the 60-64 cohort and 790 from the $65+$ cohort, yields a total of 1,479 for the period. Table 1 applies this methodology to previous years, and illustrates the dramatic uptick in departures possible in the current five-year period.

\begin{tabular}{|c|c|c|c|c|}
\hline & $\begin{array}{l}\text { Population size in } \\
\text { prior year }\end{array}$ & 60-64 departures & $65+$ departures & Total departures \\
\hline 1986 to 1990 & 8,168 & 278 & 90 & 368 \\
\hline 1990 to 1994 & 8,792 & 308 & 114 & 422 \\
\hline 1994 to 2000 & 8,634 & 203 & 104 & 307 \\
\hline 2000 to 2005 & 8,882 & 315 & 133 & 449 \\
\hline 2005 to 2010 & 9,655 & 492 & 106 & 599 \\
\hline 2010 to 2015 & 10,037 & 738 & 361 & 1,099 \\
\hline 2015 to 2020 & 10,131 & 689 & 790 & 1,479 \\
\hline
\end{tabular}

Table 1: Estimated Departures from the Two Oldest Age Cohorts of ARL Professionals, 1986 to 2020

\section{Youth Movement Starts Now?}

The delayed retirements of 2015 have almost certainly played a role in the muted hiring levels among ARL libraries in recent years, a topic I will address in a future chapter of my analysis. It is hard to see, however, how hiring could remain low. More likely, the peak vacancies we expected between 2010 and 2015 are actually happening right now, resulting in the best market for research library job seekers in memory.

The youth movement is almost certainly already in progress, but for ARL libraries, youth is not what it once was. New professionals are naturally the youngest subgroup in the population, and it is true that library schools continue to attract primarily young students, about $70 \%$ under the age of 35 in $2015 .{ }^{12}$ But ARL libraries tend to recruit 
new professionals who are somewhat older, with an average age of 35 . What's more, ARL libraries are increasingly likely to skip the hiring of new professionals and instead recruit individuals with experience: the percentage of new professionals among new hires has declined from $35 \%$ in 1986 to $26 \%$ in 2015 .

\section{A Case of Very Delayed Retirement?}

Examining the age of subgroups in the ARL population reveals that delayed retirement is a remarkably consistent phenomenon throughout the data. With the important exception of the Canadian population noted above, in 2015 we find proportionally heightened numbers of individuals aged 65+ across ARL subgroups, such as Office of Equal Opportunity and Access (OEOA) status, public or private institution, sex, region, and most jobs. Previous analyses have noted unusual aging among department heads and administrators, but in 2015, these positions no longer stand out. They remain somewhat older than other positions, a natural function of the experience they generally require, but to judge by the $65+$ age cohort, they are retiring along with everyone else.

There is one glaring exception to this rule, however, and that is library directors. Going back to 1986, we find that about 3\% of directors placed in the $65+$ cohort, matching the overall population year after year.

Then comes 2005, when the portion of directors $65+$ jumped to $35 \%$, from just $2 \%$ five years before. This extraordinary change in behavior carried on through the 2015 data, where a whopping 39\% of ARL directors were aged $65+$. 


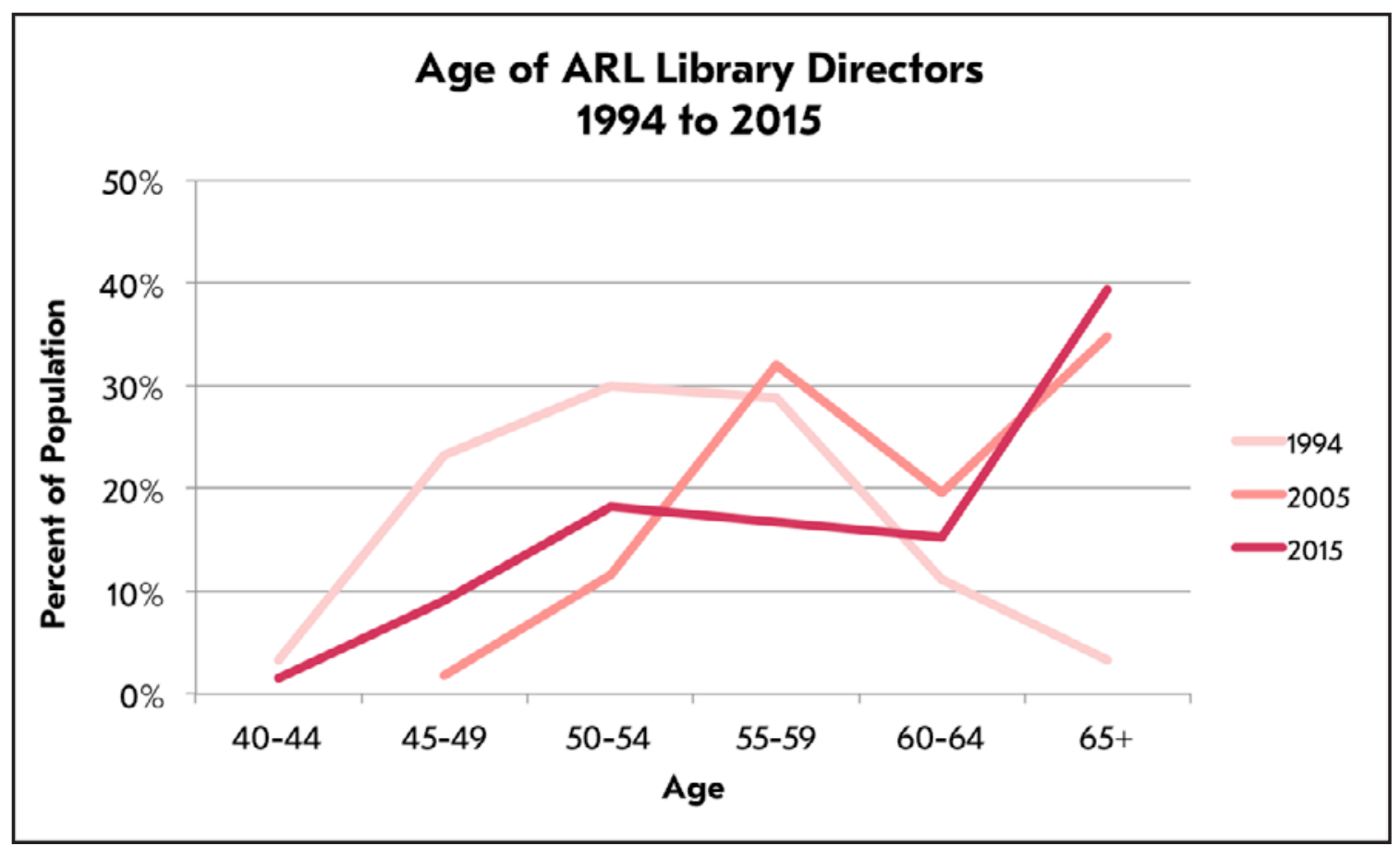

Figure 5

Mindful of the discrepancy between US and Canadians in this cohort, it makes sense to compare ARL library directors in both countries. Here we find that having isolated US directors, fully $45 \%$ of US directors were aged $65+$ in 2015 , compared to just $14 \%$ of their Canadian counterparts. Remembering that only $11 \%$ of the rest of the US ARL population was in the $65+$ age cohort, we can say with certainty that as a group US ARL directors have recently and decisively changed their behavior as regards retirement. We know that the $65+$ cohort of ARL directors is not seeing an influx of new people taking the place of retirees because the ARL Salary Survey collects data on each person's years of experience in their current library.

With nearly half of the US director population in a single age cohort $(65+)$, it is worth examining that cohort more closely. I have noted above that while the ARL population in 2015 had an unusually high percentage in the $65+$ age cohort, the number of individuals aged 70 and over was at most $1.5 \%$. This proves not to be the case for US ARL directors, 14\% of whom were aged 70 and over in 2015. 
Where is that particular trend likely to go? Even research library directors can't work indefinitely, but the assumptions underlying the estimate of departures in Table 1 clearly do not apply either. And what explains the abrupt change of behavior beginning in 2005? It could be the recession. Or maybe directors are facing increased pressure to remain in place from their administrations. It could be that the increasing gap between average compensation as reflected in the ARL Salary Survey and the compensation of directors drives that group to make different choices as to retirement.

Or is there some other reason underlying delayed retirements for US ARL directors? How far might this phenomenon go in its present direction? Will it quickly reverse course such that the director age profile once again comes to resemble that of the population as a whole?

\section{A Delayed but Significant Youth Movement}

At this writing in early 2017, the age of the population of ARL professionals echoes that of US librarians generally, and points to a period of high demand for library expertise. The net effect of the recruitments to come will be a large and important youth movement, so large that it will have only one predecessor in our recent history, the mass recruitment of young baby boomers that accompanied the extraordinary growth of higher education in the 1960s. New librarians in the 1960s were adding significantly to the size of research library professional staffing, and it is hard to imagine that the 2015-2020 recruits will do anything but fill existing vacancies. The new recruits are thus not likely to reach those heights of decades-long dominance that the 1960s hires enjoyed, but they will be disproportionately

The net effect of the recruitments to come will be a large and important youth movement... important, injecting new experience, attitudes, and aspirations into our libraries, keeping them relevant in a climate of fundamental change and uncertainty. 


\section{Endnotes}

1 The primary data source for this study is the demographic portion of the 2015 ARL Salary Survey, an unpublished data series collected by ARL. The Salary Survey includes data for all professionals working in university ARL member libraries in the US and Canada. The data tables used for the analysis presented in this article are available for download at http://www.arl.org/storage/2017-03-09-rli-wilder-data. xls.

2 Stanley Wilder, The Age Demographics of Academic Librarians:

A Profession Apart (Washington, DC: Association of Research Libraries, 1995).

3 Stanley Wilder, Demographic Change in Academic Librarianship (Washington, DC: Association of Research Libraries, 2003).

4 US Bureau of Labor Statistics, "BLS Spotlight on Statistics: The

Recession of 2007-2009,” February 2012, https://www.bls.gov/

spotlight/2012/recession/pdf/recession_bls_spotlight.pdf

5 Brooke Helppie McFall, "Crash and Wait? The Impact of the Great

Recession on the Retirement Plans of Older Americans," American

Economic Review 101, no. 3 (May 2011): 40-44.

6 Gordon Russell, "Special Report: How Startling, Unique Cuts Have

Transformed Louisiana's Universities," New Orleans Advocate,

February 12, 2016, http:/www.theadvocate.com/new_orleans/news/ education/article_6f841848-a09a-5ee7-818f-0dla43627f55.html

7 Paola Scommegna, “US Baby Boomers Likely to Delay Retirement," Population Reference Bureau, September 2014, http://www.prb.org/ Publications/Articles/2014/us-babyboomers-retirement.aspx.

8 Mitra Toossi, "Labor Force Projections to 2014: Retiring Boomers," Monthly Labor Review 128, no. 11 (November 2005): 25-44, https:// www.bls.gov/opub/mlr/2005/11/art3full.pdf; Mitra Toossi, "Labor Force Projections to 2016: More Workers in Their Golden Years," 
Monthly Labor Review 130, no. 11 (November 2007): 33-52, https:// www.bls.gov/opub/mlr/2007/11/art3full.pdf.

9 Mitra Toossi, "Labor Force Projections to 2020: A More Slowly Growing Workforce," Monthly Labor Review 135, no. 1 (January 2012): 43-64, https://www.bls.gov/opub/mlr/2012/01/art3full.pdf.

10 Mo Wang and Junqi Shi, "Psychological Research on Retirement," Annual Review of Psychology 65 (January 2014): 209-33, https://ssrn. com/abstract $=2632296$.

11 See Figure 1.

12 Association for Library and Information Science Education, ALISE Statistical Reports, 2015.

(C) 2017 Stanley Wilder

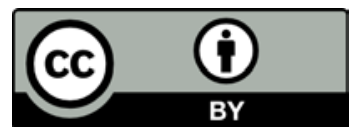

This article is licensed under a Creative Commons Attribution 4.0 International License. To view a copy of this license, visit http:// creativecommons.org/licenses/by/4.0/.

This article was previously published on the ARL website at https:// www.arl.org/focus-areas/statistics-assessment/statistical-trends.

To cite this article: Stanley Wilder. "Delayed Retirements and the Youth Movement among ARL Library Professionals.” Research Library Issues, no. 295 (2018): 6-16. https://doi.org/10.29242/rli.295.2. 


\section{Hiring and Staffing Trends in ARL Libraries}

Stanley Wilder, Dean of Libraries, Louisiana State University

We are who we hire.

As it turns out, we are also how many we hire, for what jobs, with what skills, credentials, and experience.

Hiring decisions are palpable expressions of our evolving values, and in 2015 ARL's demographic data series reflected a profession in a state of flux unlike any since the data series began in $1986 .{ }^{1}$ In some cases, change is consistent with longstanding trends, but some changes in the ARL data are recent, surprising, even counterintuitive. Taken as a whole, these changes in hiring amount to an epochal shift in the nature of library work, in what it means to be a library professional, and in the value that research libraries propose to contribute to society.

The most dramatic change relates to the rate at which ARL libraries are hiring professionals, which at first glance appears not to be undergoing epochal change at all, but rather to be simply low, in its usual way. To compare hiring rates across years, we look to the number of new hires as a percentage of the overall population. Figure 1 illustrates this approach, and suggests that in 2015, hiring was slightly lower than in past years, but not exceptionally so.

The problem with this analysis is that it assumes reasonable stability in the age profile of the population as a whole. The delayed retirements described in installment 1 of this series ${ }^{2}$ are one indication that ARL's population is anything but stable as regards to age. 


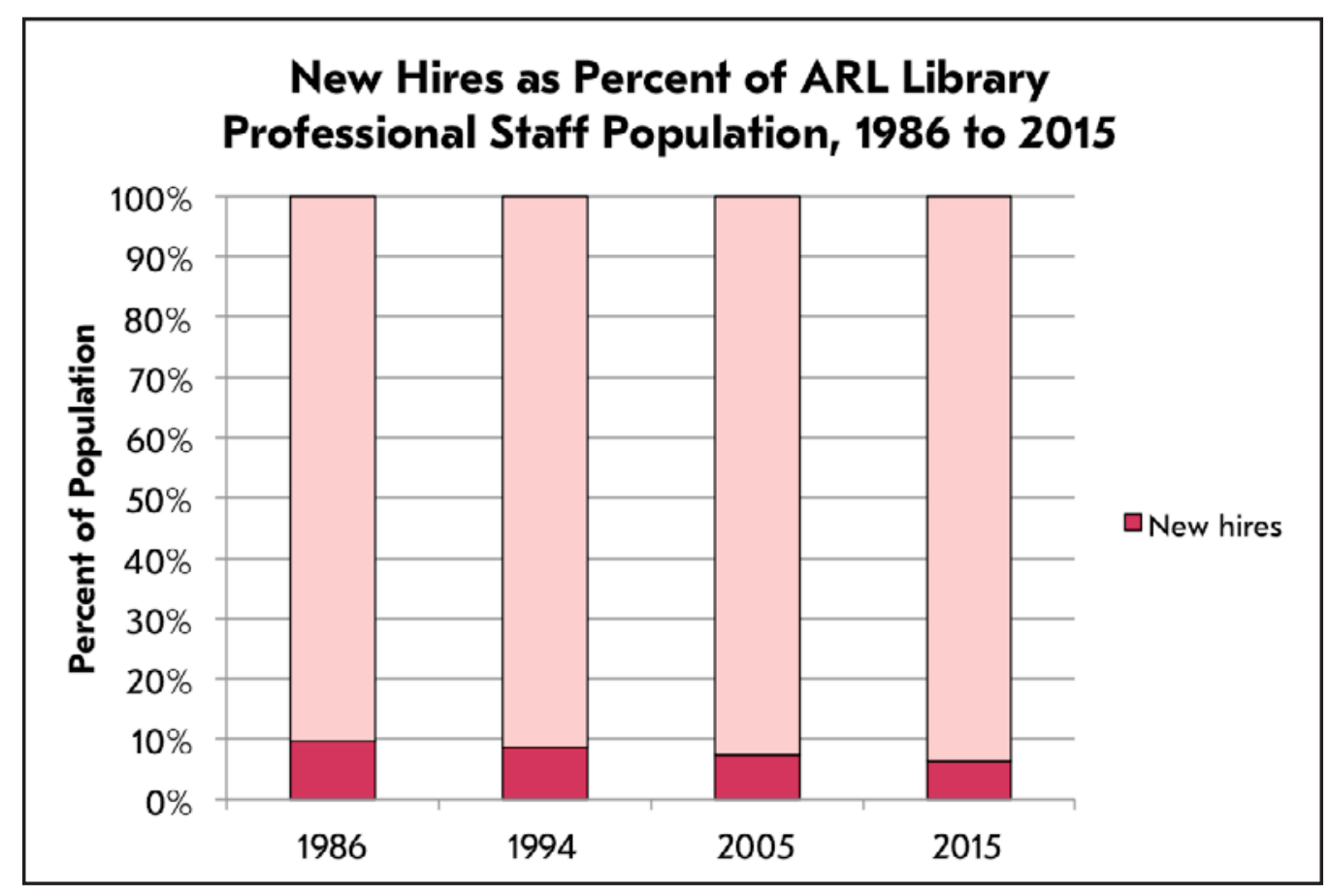

Figure 1

Figure 2 illustrates ARL's underlying hiring problem by presenting the portion of the population aged 60-64 in one data set, alongside the portion in the $65+$ cohort in the set four or five years later.

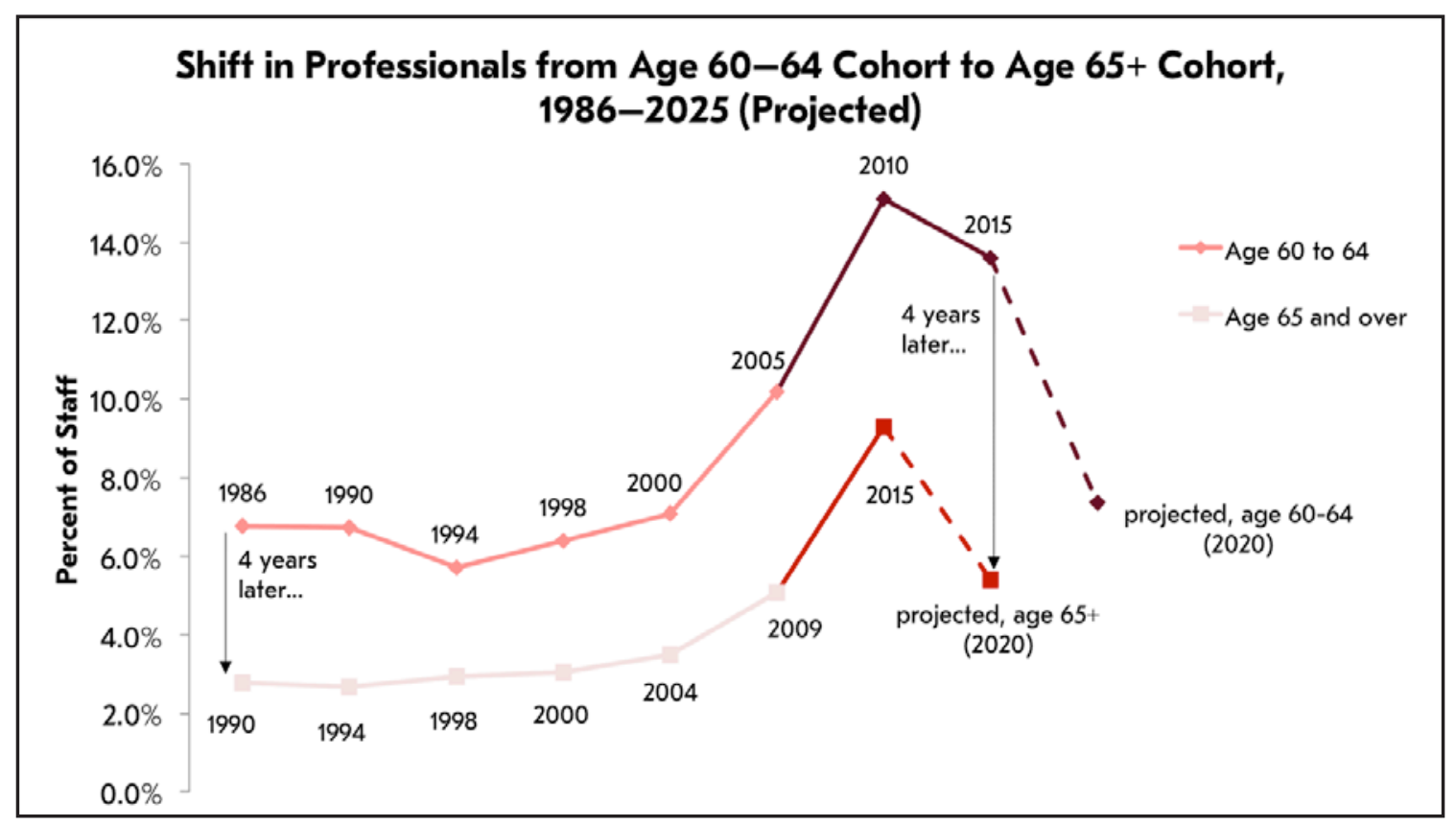

Figure 2 
As we'd expect, we see a significant drop as the individuals in the first cohort age into the next, until 2010-2015, the period in which delayed retirements became a factor. The large percentage of individuals aged 65 and over in 2015 is an aberration, and it begs the question as to what will happen to this group in the 2020 data.

This happens to be a question we can answer with reasonable certainty. The key lies in isolating those individuals aged 70 and over across the data sets. Doing so reveals that very few ARL professionals work past age 70 , about $1 \%$ in every data set since 1986 . It is certainly possible that, in 2020, those who were in the 65+ cohort in 2015 might suddenly prove to be the first to work past 70 in large numbers, but this is highly unlikely. The 2020 data will almost certainly reflect the retirement of at least $8 \%$ of the ARL population from the $201565+$ cohort alone, the equivalent of over 800 individuals. (See Figure 3.) For perspective, $8 \%$ retirement in this cohort would be 2.5 times the number retiring between 2005 and 2010, and almost 5 times the number retiring between 2000 and 2005 .

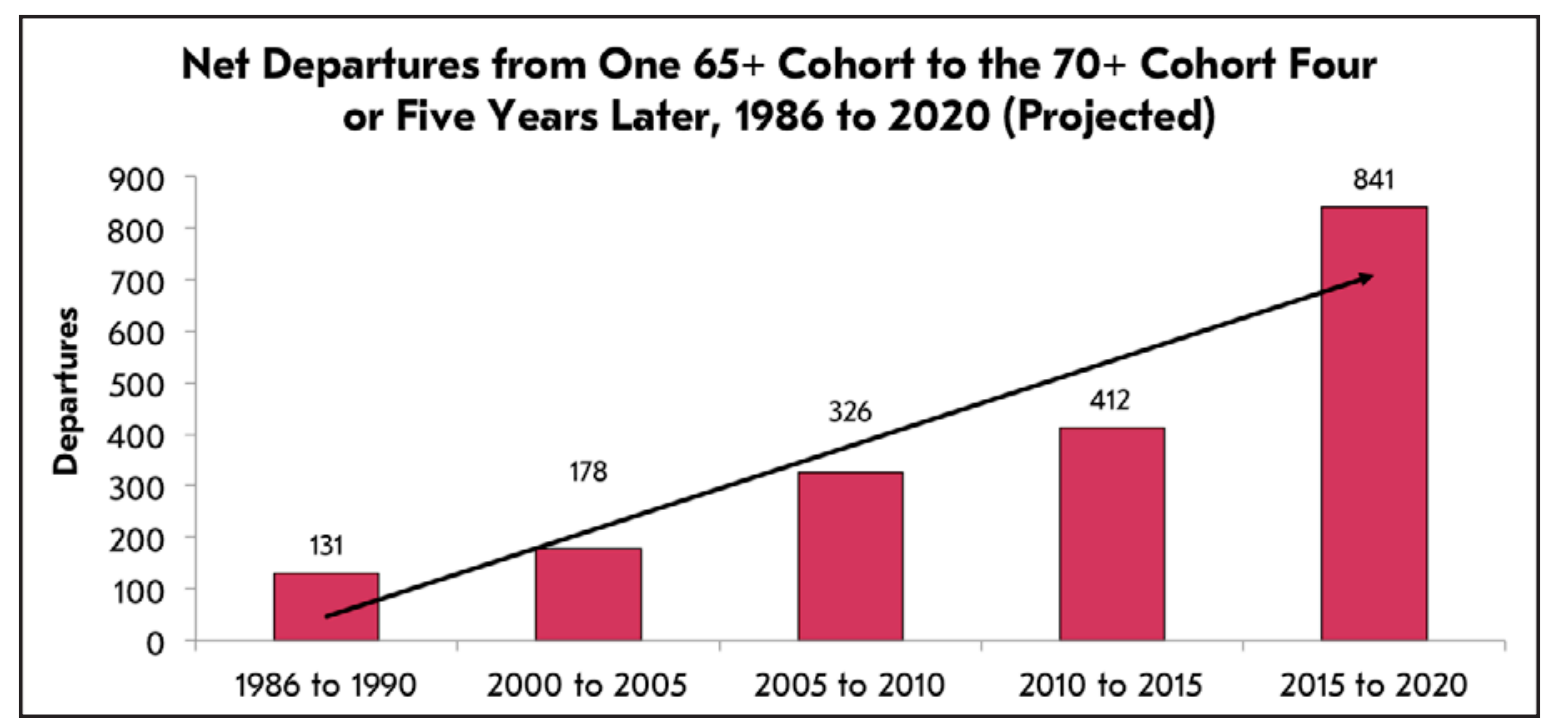

Figure 3

Given the imminent surge of retirements from the oldest age cohort, it is worth asking whether the vacancies that result will be filled on a one-to-one basis. Money for positions is precious and often fraught politically, but here again, the data are clear in support of replacement 
hiring of professionals. Collectively, ARL libraries have increasednot decreased-the employment of professionals, even through the recession of 2008. (See Figure 4.) The demographic data don't speak directly to replacement decisions at the individual level, but in the ARL Statistics, the median number of professionals has grown at a rate of about $1 \%$ per year since $1985 .^{3}$

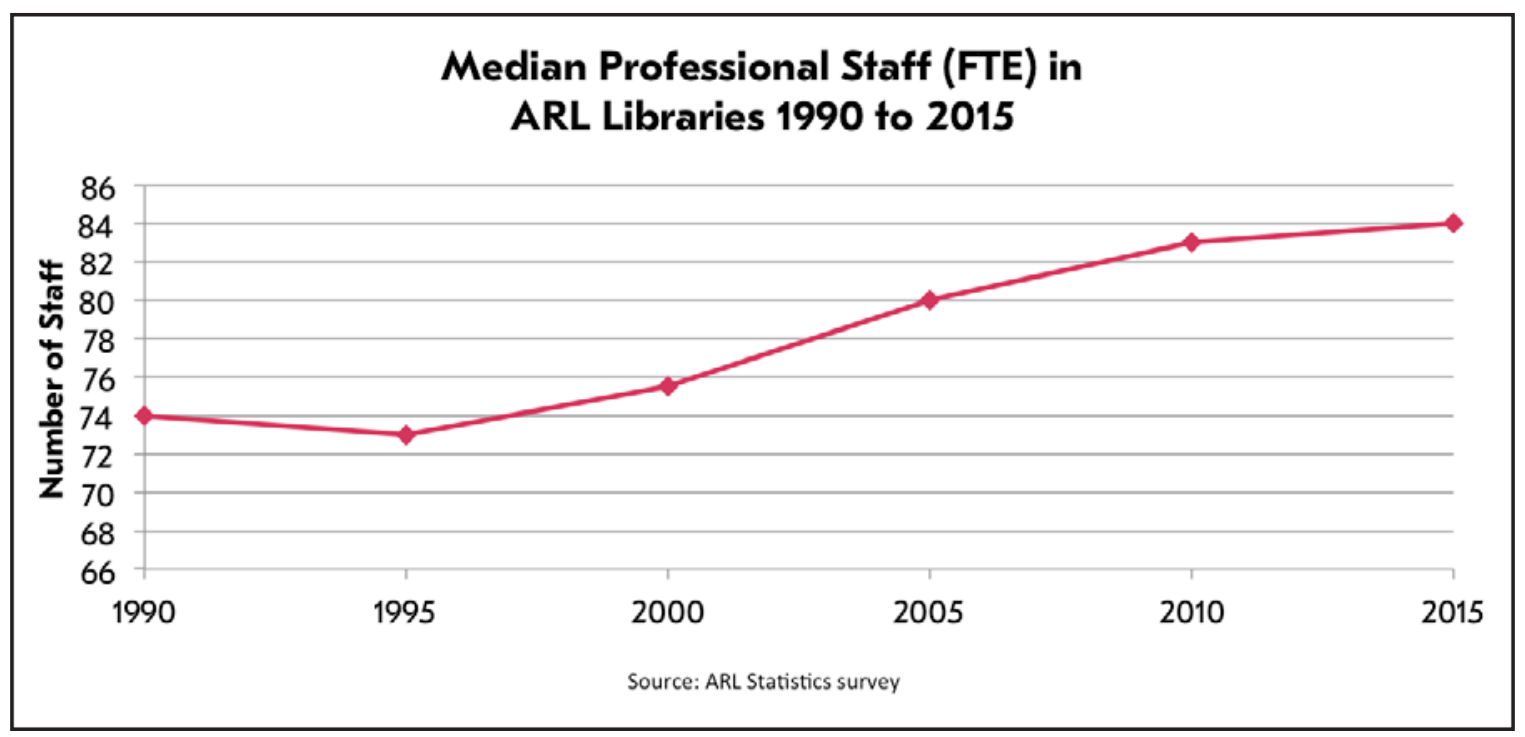

Figure 4

In sum, while hiring was low in 2015, it would not have been were it not for an unexpected surge in delayed retirements. Looking forward, the combination of high numbers of individuals aged $65^{+}$, the low likelihood that they will work past 70, and the strong tendency on the part of libraries to fill professional vacancies means that the 2015-2020 period is almost certain to require more hiring than any time since 1985. This is a great time to be looking for a job in an ARL library.

\section{Continued Rise of Nontraditional Professional Jobs}

It is one thing for a library to fill vacated professional positions on a one-to-one basis, but quite another for those positions to be refilled in the same jobs that produced the vacancies. Libraries normally use vacant positions to do just that-a vacancy in cataloging, for example, is usually used to recruit another cataloger. But each vacancy is also 
an opportunity to address new needs that can help the library adapt to changes on campus and the broader external environment.

New hires are the best indication we have as to current demand for various kinds of professional expertise. In 2015, the ARL Salary Survey included 21 job categories, but hiring is by no means evenly distributed among those categories. Figure 5 compares the six job categories that had the most new hires in 1986 and 2015. Though the top six categories were different in 1986 and 2015, in both years employees in these categories accounted for over $70 \%$ of all new hires.

Figure 5 illustrates that tracking job categories across years in the ARL demographic data is inherently messy, as these categories have evolved rapidly in an effort to keep pace with emerging staffing needs. For that matter, most of the changes in job categories have been driven by the explosive growth in nontraditional library professional jobs. I define nontraditional jobs to be those for which the primary expertise requirement lies in fields beyond librarianship, for example computing, financial, legal, human resources, and so on.

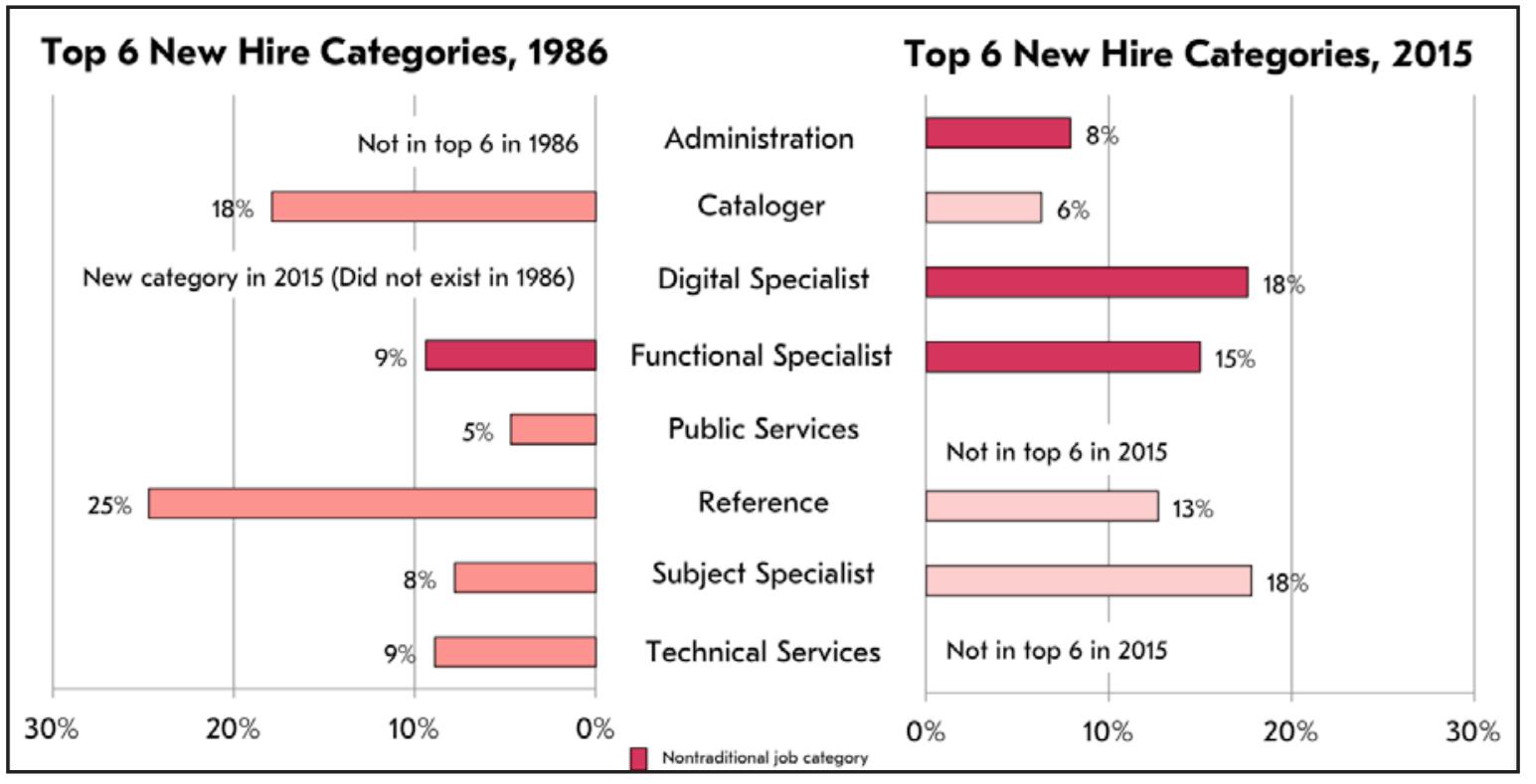

Figure 5 
Thus defined, the 1986 list has only one nontraditional position, functional specialist, which accounted for only $9 \%$ of new hires that year. The comparable list for 2015 has nontraditional jobs in three of the top six job categories-digital specialist, functional specialist, and administration-comprising $41 \%$ of all new hires. Hiring for nontraditionals has grown consistently throughout the years, and in 2015 the data show no sign of this trend abating.

Nontraditionals among 2015 new hires are notable for being more male than traditionals ( $41 \%$ of nontraditional new hires were male vs. $28 \%$ of traditional new hires) and they're more likely to have no library degree ( $40 \%$ of nontraditional new hires do not have library degrees vs. only $8 \%$ of traditional new hires). It is interesting that while ARL libraries

...the 2015-2020 period is almost certain to require more hiring than any time since 1985. have added thousands of nontraditionals since 1986, these hires haven't altered ARL's gender mix, as always about $63 \%$ female. The hiring of nontraditionals has had a pronounced impact on credentialing for the profession, however, and has lowered the profile of library education in the process.

The emergence of nontraditional professionals is not an indication that demand for traditional library expertise is likely to disappear anytime soon. For example, we might be concerned about hiring for reference librarians, down from one in four hires in 1986 to just over one in ten in 2015. It is possible, however, that this decline is simply the result of a shift in focus for public service professionals, away from reference desks and towards work better captured by the subject specialist category. The total number of professionals in the reference and subject specialist job categories combined shows virtually no change in hiring priority between 1986 and 2015.

No such combination of job categories, however, can save cataloging from its decline as a hiring priority. If we allow for overlap in the functional duties of catalogers and technical services librarians, for 
example, we still find a steep reduction in hiring, from $26 \%$ of new hires in 1986, to just 8\% in 2015.

Such is the long, steep decline in cataloger hiring that we may be relieved to find that, as of 2015, it appears to have leveled off. Throughout the data series, hiring of catalogers lagged below the percent of catalogers in the larger population, meaning that vacancies in cataloging positions were not being filled with new hires on a one-to-one basis. This changed in 2015, when these two percentages matched exactly.

And yet the future of cataloging feels as tenuous as ever: As Figure 6 attests, $13 \%$ of ARL catalogers were aged $65+$ in 2015, and, as Figure 8 shows, $30 \%$ were aged $60+$.

\begin{tabular}{|l|c|c|c|}
\hline \multicolumn{4}{|c|}{$\begin{array}{l}\text { Job Categories with the Largest Percentage of } \\
\text { Employees Aged 65+ in ARL Libraries, 2015 }\end{array}$} \\
\hline & N & Percentage & $\begin{array}{c}\text { Number of professionals aged 65+ in 2015 likely to have } \\
\text { retired by 2020 }\end{array}$ \\
\hline Director & 114 & $39 \%$ & 44 \\
\hline Head, Serials & 3 & $33 \%$ & 1 \\
\hline Head, Law & 72 & $24 \%$ & 17 \\
\hline Head, Rare books & 119 & $21 \%$ & 24 \\
\hline Head, Acquisitions & 160 & $17 \%$ & 26 \\
\hline Head, Medical & 64 & $17 \%$ & 10 \\
\hline Head, Cataloging & 183 & $17 \%$ & 28 \\
\hline Head, Branch & 385 & $16 \%$ & 57 \\
\hline Cataloger & 659 & $13 \%$ & 80 \\
\hline Head, Reference & 176 & $13 \%$ & 20 \\
\hline Head, Other & 646 & $10 \%$ & 61 \\
\hline Head, Circulation & 157 & $10 \%$ & 15 \\
\hline
\end{tabular}

Figure 6

For the one-to-one replacement in 2015 to continue, unusually high levels of retirements will mean that libraries are likely to have difficulty replacing cataloging expertise in the near term.

\section{Present and Near-Term Demand for Job Categories}

The case of cataloging presented above is an illustration of how the demographic data can help estimate current and near-term demand for each of the ARL job categories. The strength of current demand 
for job categories can be measured by comparing a job's percentage of new hires to its percentage of the overall population. For example, if a job's percent of new hires were significantly lower than its percent of population, we'd conclude that demand for that specialization is weak. Figure 7 presents the 21 job categories from 2015, sorted from high demand to low.

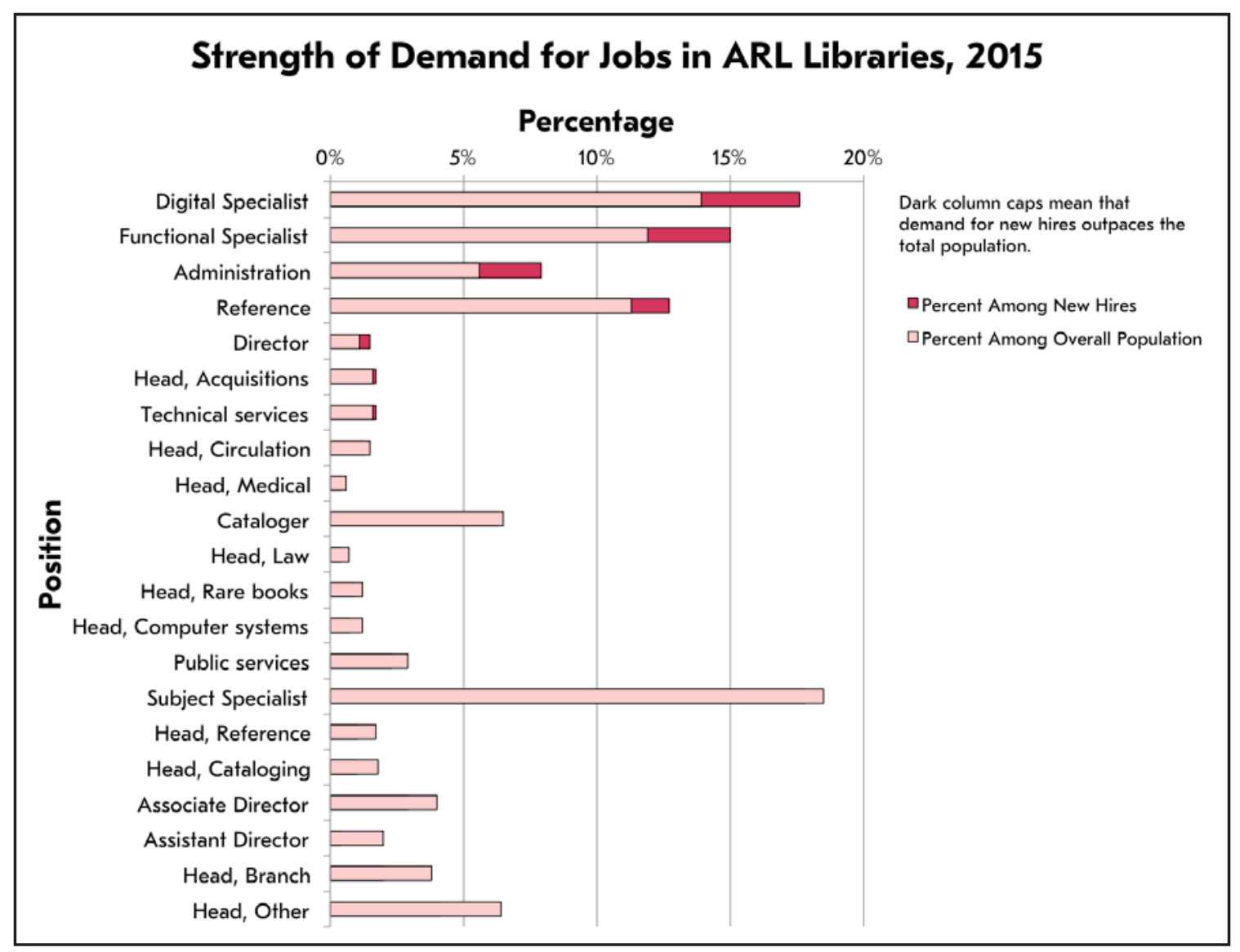

Figure 7

Prospects for near-term demand for each job category can be inferred from the relative concentration of individuals in the retirement-prone $60+$ age cohort. Figure 8 presents the jobs with either an unusually high or an unusually low percentage of individuals in the 60+ age cohort. 


\begin{tabular}{|c|c|c|c|}
\hline \multicolumn{4}{|c|}{$\begin{array}{l}\text { Job Categories with the Largest Percentage of Oldest and } \\
\text { Youngest Professionals in ARL Libraries, } 2015\end{array}$} \\
\hline \multicolumn{2}{|c|}{$\begin{array}{c}\text { Job categories with the Largest } \\
\text { Percentage of Professionals Age } \\
60+\end{array}$} & \multicolumn{2}{|c|}{\begin{tabular}{|c|} 
Job cafegories with the Largest \\
Percentage of Professionals Under Age \\
30
\end{tabular}} \\
\hline & $\%$ Age $60+$ & & \% Under Age 30 \\
\hline Director & $54.6 \%$ & \begin{tabular}{|l} 
Public services \\
\end{tabular} & $8.2 \%$ \\
\hline Head, Law & $45.4 \%$ & Functional Specialist & $7.1 \%$ \\
\hline Head, Medical & $43.4 \%$ & \begin{tabular}{|l} 
Digital Specialist \\
\end{tabular} & $7.1 \%$ \\
\hline Head, Cataloging & $37.4 \%$ & \begin{tabular}{|l|} 
Reference \\
\end{tabular} & $6.0 \%$ \\
\hline Head, Rare books & $37.3 \%$ & \begin{tabular}{|l} 
Technical services \\
\end{tabular} & $5.0 \%$ \\
\hline Head, Branch & $34.1 \%$ & \begin{tabular}{|l} 
Subject Specialist \\
Subject
\end{tabular} & $4.0 \%$ \\
\hline Head, Serials & $33.3 \%$ & & \\
\hline Associate Director & $32.4 \%$ & & \\
\hline Head, Reference & $31.5 \%$ & & \\
\hline Head, Acquisitions & $30.9 \%$ & & \\
\hline Cataloger & $30.4 \%$ & & \\
\hline
\end{tabular}

Figure 8

\section{The Special Case of Library Leadership}

It is striking that all but one of the job categories in Figure 6 are administrative or managerial. ARL libraries are almost certain to be in the midst of an unprecedented changing of the guard in leadership. Those who hold these positions currently face an urgent need to attend to succession planning, mentorship, and organizational design. For everyone who aspires to such positions, there will likely never be a better time to apply. As for the profession at large, the impact of the incoming generation of library leaders will be unusually strong and long lasting.

\section{New Hires and the MLS Degree}

Positions in the traditional job categories generally require a formal library education, and those hired for these positions are only slightly less likely than in years past to have no library degree. There are serious causes for concern for library education, however. The emergence of significant numbers of nontraditional professionals, $71 \%$ of whom have no library credential, has reduced the overall percentage of ARL professionals with a library degree from $92 \%$ in 1986 to $83 \%$ in 2015 . The overall percentage of ARL professionals with a library degree is 
likely to decline further over the coming years.

An additional cause for concern relates to compensation, where those with no library degree actually enjoy an advantage. Among 2015 new hires, $59 \%$ of those with no library degree were hired for salaries of $\$ 60,000$ or higher, compared with $51 \%$ of those with a library credential.

\section{Professional Hiring in the Context of Overall Library Staffing}

Nearly everything in the preceding analysis concerns ARL professionals in isolation. Professionals certainly play an outsized role in designing and delivering library services, but they accounted for only $39 \%$ of the ARL library workforce in 2015. Such is the interdependence of library work that it's not possible to fully understand professional staffing, to say nothing of library staffing generally, without reference to support staff and student assistants.

Analysis of student and support staff proves difficult in practice, however. The paucity of data relating to these groups stands in stark contrast to the richness of that for professionals. Student and support staff are nearly invisible in library data sets generally, although recent initiatives show signs of improvement. ${ }^{4}$

The ARL Statistics data do track student and support staff full-time equivalents (FTE) and expenditures, and the FTE figures provide a vivid illustration of how staffing dynamics among these groups warrant deeper understanding. For example, it is significant that overall library staffing, as measured by median FTE, has been in gradual decline since 1990, and in sharp decline since 2005. (See Figure 9.) Research library work is becoming sharply less labor intensive, and there is little reason to 
expect this trend will reverse itself anytime soon.

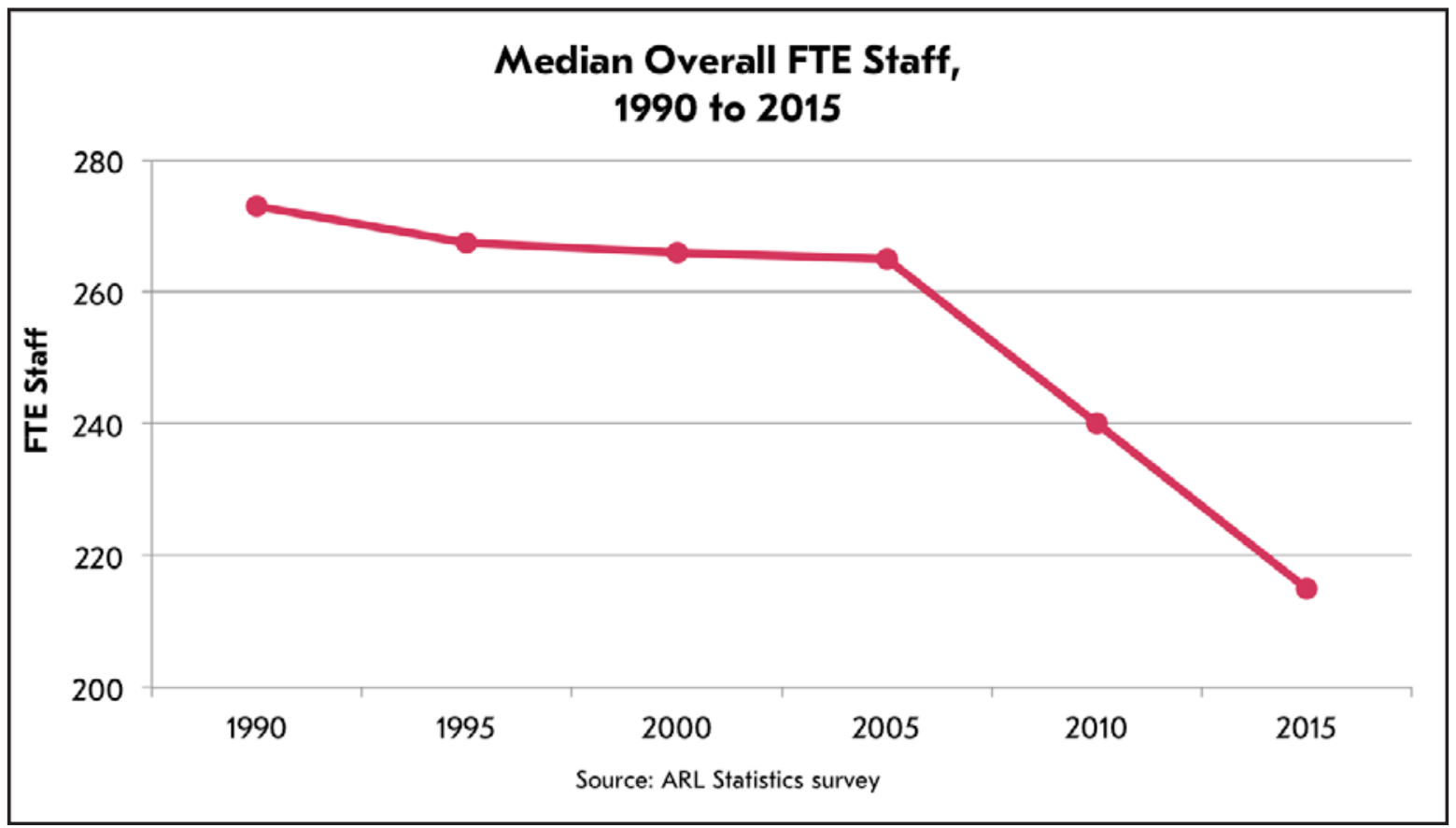

Figure 9

The data on library staff collected by the US Current Population Survey (CPS) appear to reflect this trend as well. The CPS produces annual, unpublished data relating the number, age, and sex of library professionals and support staff. This data is significantly different from the ARL data in that it is based on sampling, not self-report, and includes individuals working in all types of libraries. The CPS data has nonetheless mirrored ARL's as to age for decades, but the estimated number of individuals in both the professional and support staff occupations has been volatile, perhaps not surprising given the small size of the library profession.

So while the ARL data has the number of professionals increasing, the CPS data has it declining precipitously. Another significant difference between the two sets is that professionals outnumber support staff by at least four to one in the CPS data. Whatever these discrepancies may mean for its reliability, it is remarkable that the 2015 CPS data set has the number of individuals in both the professional and support staff occupation categories dropping by about $15 \%$ in just one year, reaching 
historic lows. (See Figure 10.)

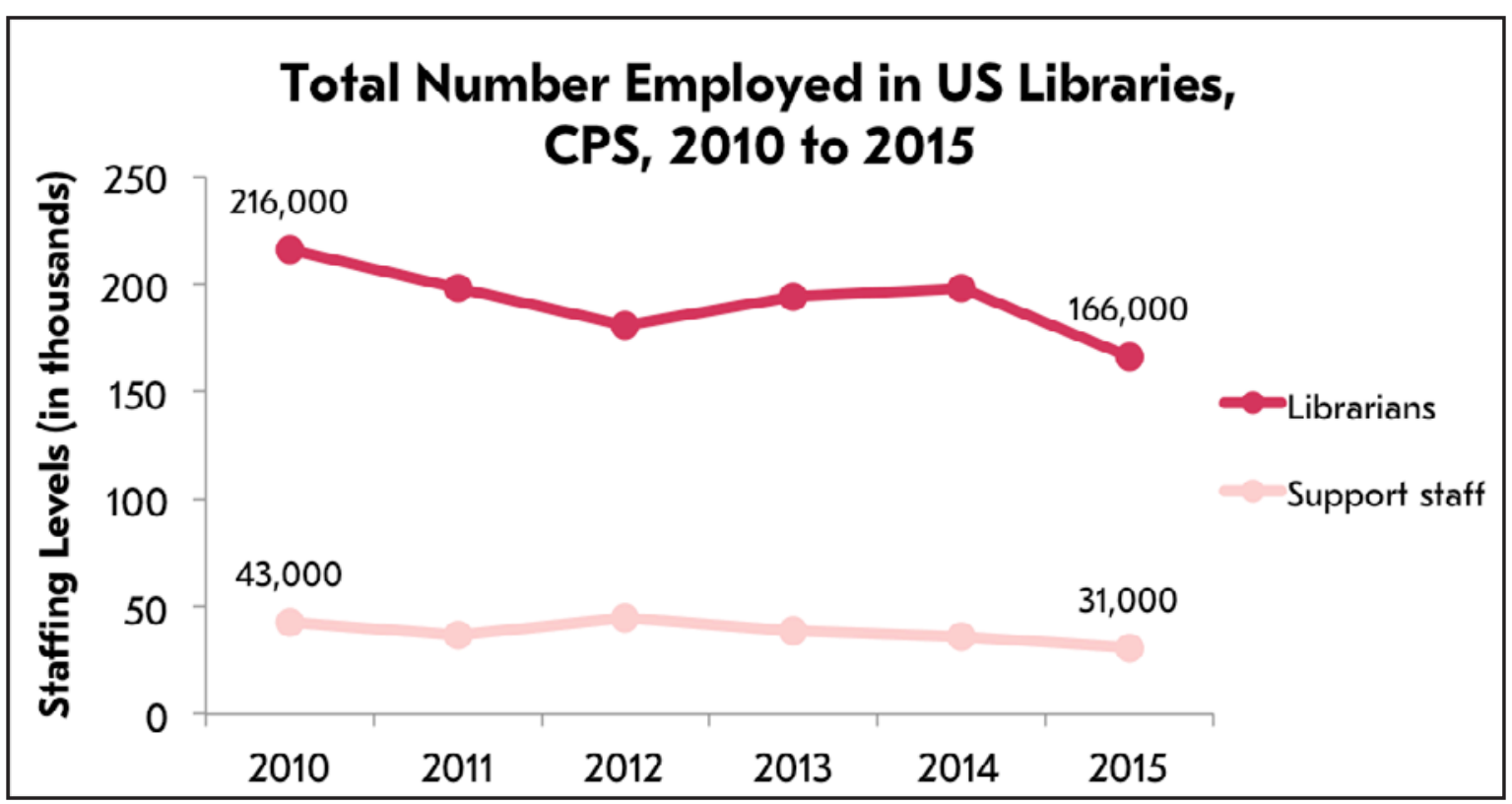

Figure 10

Overall staffing is declining because lower-skill work is disappearing. I wrote about this phenomenon in a short piece based on the 2010 ARL Statistics, but it merits revisiting for having accelerated dramatically since then. ${ }^{5}$ Figure 11 illustrates that the decline in overall median FTE owes entirely to the student and support staff categories.

Median student staffing is down 33\% since 2000, with about one-third of that decline occurring in just the $2010-2015$ period. The $27 \%$ decline among support staff in that period is only slightly less dramatic. 


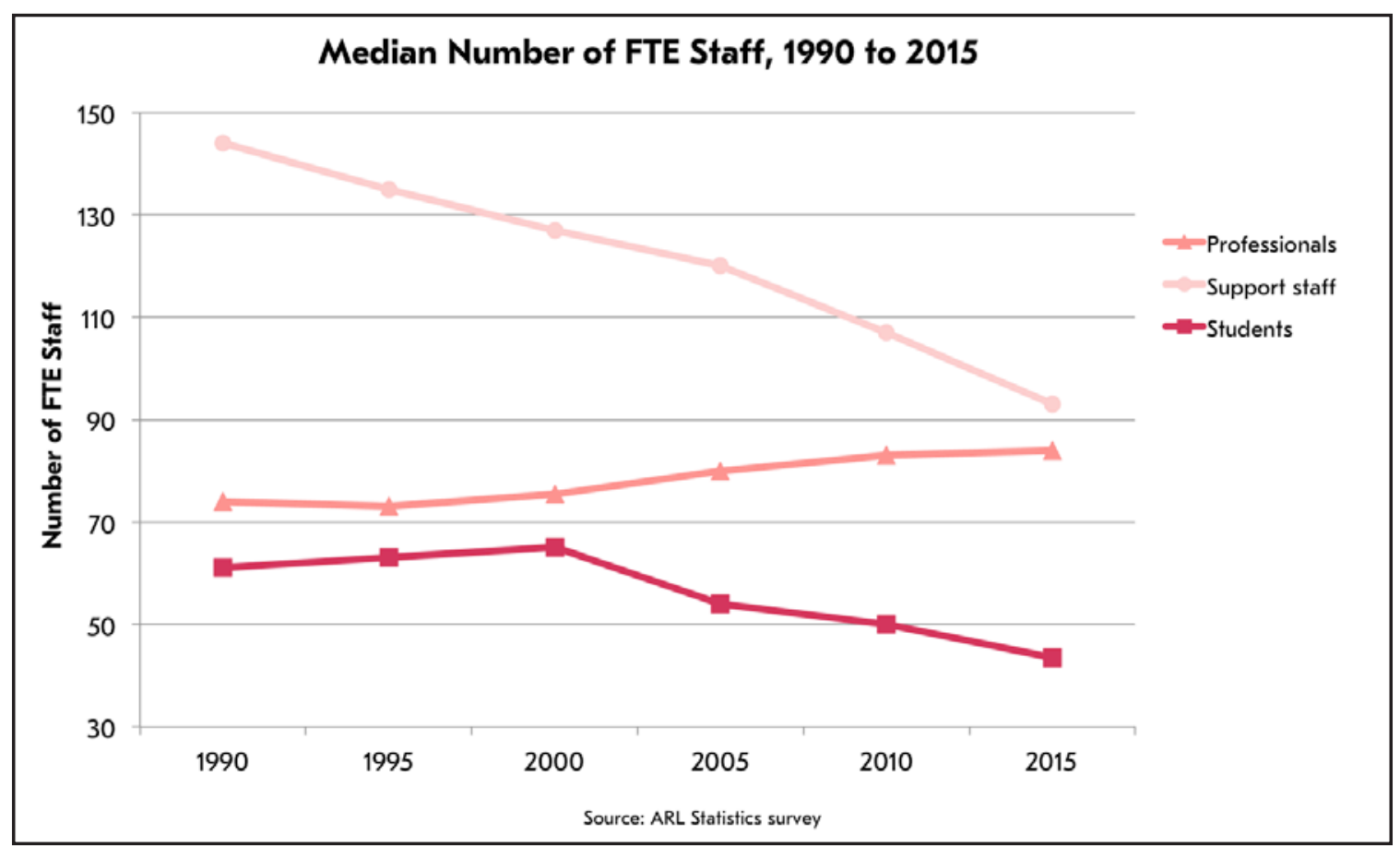

Figure 11

This is the context for understanding the steady increase in professional staffing reflected in Figure 4. Since 2000, the student and support staff share of total staffing declined from $72 \%$ to $62 \%$. Put another way, in 1990, a typical ARL library had twice as many support staff as professionals. By 2015 support staff held only an 11\% advantage. If this trend continues, in the next few years we will see professionals outnumber support staff for the first time.

The underlying narrative places research library staffing squarely in the mainstream of global labor force trends, wherein lower-skill, repetitive, piece-work oriented tasks are disappearing, replaced by networks and technologies. To this, research librarianship can add the nearly wholesale migration of scholarship from print to digital formats. The impact of these environmental changes on the library workforce cannot be overstated. Lower-skill tasks are indeed disappearing, and they will never come back.

In their place, the emerging library workforce will be smaller, younger, with higher levels of more diverse skills. It will draw from a broader 
spectrum of credentialing, and enjoy better compensation, a reflection of the broader market for the skills they bring. The period of 20152020 will prove a watershed moment for research library staffing, and will herald the start of the next generation of library professionals.

\section{Endnotes}

1 The primary data source for this study is the demographic portion of the 2015 ARL Salary Survey, an unpublished data series collected by ARL. The Salary Survey includes data for all professionals working in university ARL member libraries in the US and Canada. The data tables used for the analysis presented in this article are available for download at http://www.arl.org/storage/2017-10-03-rli-wilder-data. xls.

2 Stanley Wilder, "Delayed Retirements and the Youth Movement among ARL Library Professionals," Workforce Trends in Research Libraries series, March 2017, http://www.arl.org/workforce-trends.

3 Association of Research Libraries, ARL Statistics Analytics, accessed September 29, 2017, https://www.arlstatistics.org/analytics.

4 Roger C. Schonfeld and Liam Sweeney, Inclusion, Diversity, and Equity: Members of the Association of Research Libraries: Employee Demographics and Director Perspectives, August 30, 2017, https://doi. org/10.18665/sr.304524.

5 Stanley Wilder, "The End of Lower Skill Employment in Research Libraries," BackTalk, Library Journal, June 24, 2013, http://lj.libraryjournal.com/2013/06/opinion/backtalk/ the-end-of-lower-skill-employment-in-research-libraries-backtalk/

(C) 2017 Stanley Wilder

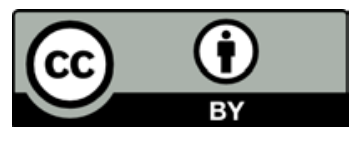

This article is licensed under a Creative Commons Attribution 4.0 International License. To view a copy of this license, visit http:// 
creativecommons.org/licenses/by/4.0/.

This article was previously published on the ARL website at https:// www.arl.org/focus-areas/statistics-assessment/statistical-trends.

To cite this article: Stanley Wilder. "Hiring and Staffing Trends in ARL Libraries.” Research Library Issues, no. 295 (2018): 17-31. https:// doi.org/10.29242/rli.295.3. 


\title{
Selected Demographic Trends in the ARL Professional Population
}

\author{
Stanley Wilder, Dean of Libraries, Louisiana State University
}

Previous analyses of the 2015 demographic data from the Association of Research Libraries (ARL) have focused on population-wide issues such as retirements, hiring patterns, and the emerging youth movement. But the 10,000-plus population of professionals ${ }^{1}$ in this data also contains multitudes: identifiable groups of individuals, some of which have different, even surprising characteristics. Some of these characteristics may relate to practical managerial concerns, while others speak to our values as a profession, or our concern for basic fairness. The following analysis focuses on four such demographic groups:

Canadians; historically underrepresented racial and ethnic groups; women; and millennials. The identification of these groups, and the differences noted among them, owe much to the ...the 10,000-plus population of [ARL] professionals...contains multitudes.... Some of these characteristics may relate to practical managerial concerns, while others speak to our values as a profession, or our concern for basic fairness. nature of the data we happen to have available. The ARL demographic data series is among the strongest such professional data in existence, but it has all the limitations inherent in such long-standing, and strictly quantitative data. That said, there is beauty in ARL's multitudes.

\section{Canadian Salary Advantage}

Advice to salary-conscious research library professionals with a tolerance for cold weather: move to Canada, early and often. When the ARL Salary Survey data combines US and Canadian libraries, salaries are expressed in terms of US dollars. ${ }^{2}$ In 2015, professional salaries among the 16 Canadian ARL libraries were significantly higher than 
those in US libraries, and uniformly so across all income ranges. At the high-income end, for example, 39\% of Canadian ARL professionals earned adjusted salaries of $\$ 100,000$ or more, compared to just $14 \%$ of those in the US.

The discrepancy is equally stark at the low-income end of the spectrum. In the US, $28 \%$ of ARL professionals had salaries below $\$ 60,000$, compared to just $7 \%$ of

Advice to salaryconscious research library professionals with a tolerance for cold weather: move to Canada, early and often. Canadian professionals. Comparing the salaries of individuals with either zero or one year of professional experience gives further insight into the Canadian salary advantage. Fully $81 \%$ of those new professionals in Canadian libraries earned $\$ 60,000$ and over, double the $40 \%$ of their colleagues in the US.

Have Canadian ARL salaries always been higher than US ARL salaries? I have salary cohort data for the 2005, 2010, and 2015 data sets. (See Table 1.) Curiously, the 2005 data shows virtually no disparity between US and Canadian ARL professionals. The disparity sets in by the 2010 data, however, which looks very similar to the 2015 data.

\begin{tabular}{|c|c|c|c|c|c|c|}
\hline & \multicolumn{2}{|l|}{2005} & \multicolumn{2}{|l|}{2010} & \multicolumn{2}{|l|}{2015} \\
\hline & $\begin{array}{l}\text { Under } \\
\$ 60,000\end{array}$ & $\begin{array}{l}\$ 100,000 \\
\text { and up }\end{array}$ & $\begin{array}{l}\text { Under } \\
\$ 60,000\end{array}$ & $\begin{array}{l}\$ 100,000 \\
\text { and up }\end{array}$ & $\begin{array}{l}\text { Under } \\
\$ 60,000\end{array}$ & $\begin{array}{l}\$ 100,000 \\
\text { and up }\end{array}$ \\
\hline Canada & $57 \%$ & $2 \%$ & $7 \%$ & $39 \%$ & $7 \%$ & $39 \%$ \\
\hline US & $56 \%$ & $6 \%$ & $39 \%$ & $10 \%$ & $28 \%$ & $14 \%$ \\
\hline
\end{tabular}

Table 1: Percentage of ARL Professionals Earning Less Than $\$ 60,000$ and Earning $\$ 100,000$ or More, by Country, in 2005, 2010, 2015

Canada has a higher percentage of new hires (10\% of the population of ARL professionals in Canada have zero to one year of experience in their current institution compared to 7\% for the US) and also of new professionals ( $6 \%$ of the population compared to $4 \%$ for the US). Better pay and more hiring are factors that bode well for the future of 
Canadian ARL libraries.

It is easy to imagine a broad range of possible explanations for the US/ Canadian salary disparities, but the ARL data can do little more than eliminate some of them. For example, Canadian professionals do not have higher percentages of professional experience, $\mathrm{PhD}$ degrees, or supervisory positions. To be sure, there are some modest differences between the two groups: Canadians are somewhat more female $(69 \%$ compared to $63 \%$ in the US), and somewhat younger ( $45 \%$ under 45 compared to $39 \%$ in the US). None of these differences seem likely to explain the salary differences, however. I suspect that the primary drivers are macroeconomic in nature, and outside the scope of this study.

\section{Historically Underrepresented Groups}

The demographic profile of historically underrepresented groups in professional positions in US ARL university libraries is frustrating in that 2015 proved to be yet another year in a series that has exhibited only excruciatingly slow improvement. ${ }^{3}$ (See Figure 1.) The Caucasian portion of the population fell in the 35 years between 1980 and 2015, but only slightly, from $88.6 \%$ to $85.1 \%$. This metric alone can't support the conclusion that our diversity efforts have failed. It's always possible that without these efforts, our situation could have gotten worse! But our profession aspires to far greater progress in this area, and the 2015 data should spur commitment to redoubled efforts, or entirely new efforts, or both. 


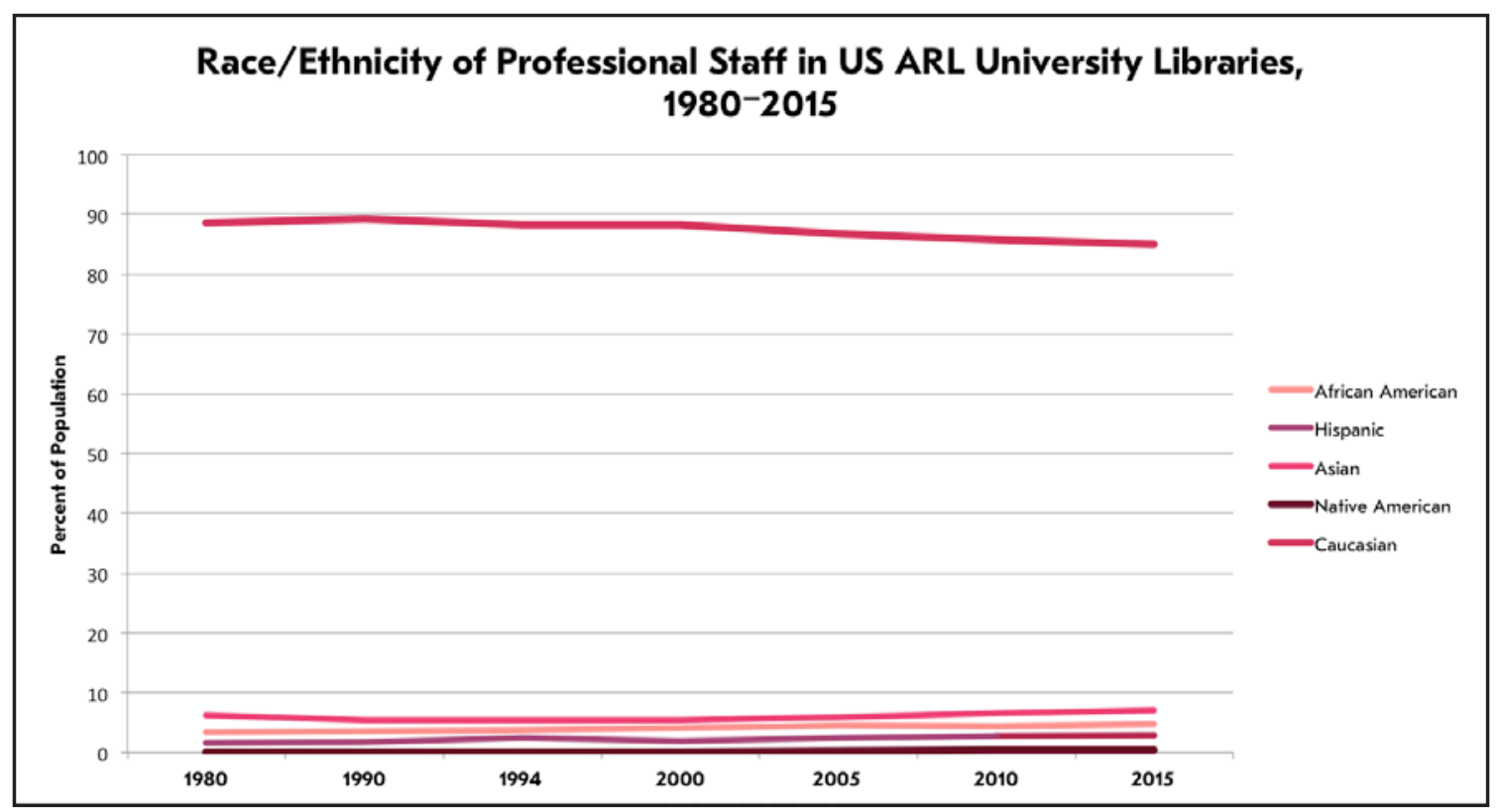

Figure 1

Eliminating the Caucasian trendline and tweaking the scale on the "percent of population" axis allows us to highlight the growth in diversity that has occurred. (See Figure 2.) All of the underrepresented racial and ethnic groups increase in the period, and the Hispanic portion of the population nearly doubles, albeit from a very small number in 1980.

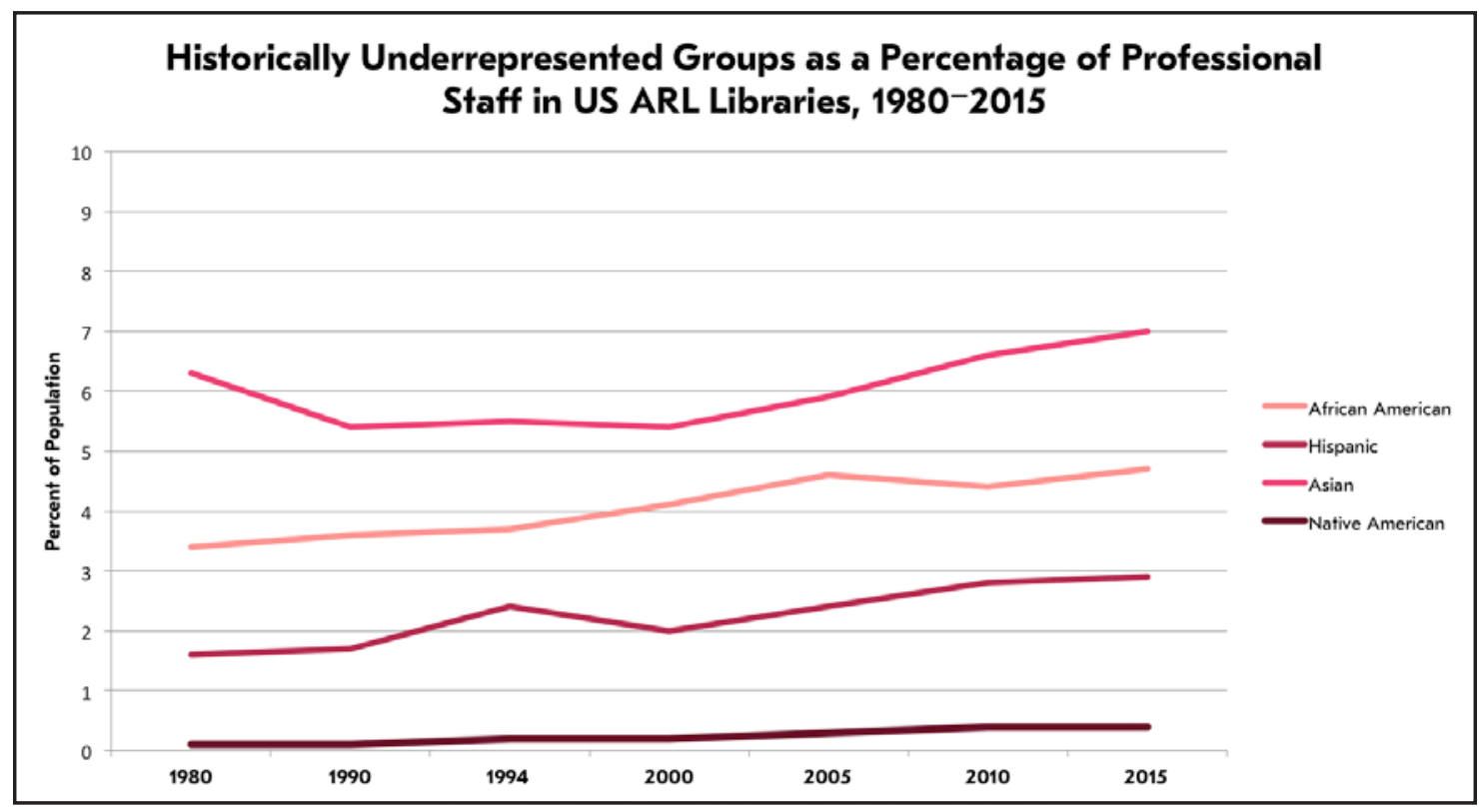

Figure 2 
There are modest disparities in diversity by region, with western ARL libraries exhibiting the smallest percentage of Caucasian professionals. (See Table 2.)

\begin{tabular}{|l|r|r|r|r|}
\hline & Northeast & North Central & \multicolumn{1}{|c|}{ South } & West \\
\hline $\begin{array}{l}\text { Native American or } \\
\text { Native Alaskan }\end{array}$ & $0.2 \%$ & $0.3 \%$ & $0 \%$ & $1 \%$ \\
\hline $\begin{array}{l}\text { Asian or Pacific Islander } \\
\text { African American }\end{array}$ & $7 \%$ & $5 \%$ & $5 \%$ & $13 \%$ \\
\hline $\begin{array}{l}\text { Caucasian } \\
\text { Hispanic }\end{array}$ & $4 \%$ & $5 \%$ & $6 \%$ & $3 \%$ \\
\hline Total & $100 \%$ & $87 \%$ & $85 \%$ & $78 \%$ \\
\hline
\end{tabular}

Table 2: Race/Ethnicity of Professional Staff in US ARL University Libraries by Region, 2015

Another measure of diversity across US ARL libraries is the distribution of racial and ethnic groups across these broad regions. (See Table 3.) If these groups were equally represented according to region, we would expect to see $25 \%$ throughout. There are some notable disparities throughout, however, possibly the result of regional differences in the distribution of racial and ethnic groups in the broader US population. ${ }^{4}$ While ARL libraries routinely recruit nationally for most professional positions, regional and local labor markets surely play an important role.

\begin{tabular}{|l|r|r|r|r|r|}
\hline & Northeast & North Central & South & West & Total \\
\hline $\begin{array}{l}\text { Native American or } \\
\text { Native Alaskan }\end{array}$ & $17 \%$ & $20 \%$ & $20 \%$ & $43 \%$ & $100 \%$ \\
\hline Asian or Pacific Islander & $31 \%$ & $18 \%$ & $23 \%$ & $27 \%$ & $100 \%$ \\
\hline African American & $24 \%$ & $24 \%$ & $42 \%$ & $10 \%$ & $100 \%$ \\
\hline Caucasian & $31 \%$ & $24 \%$ & $32 \%$ & $14 \%$ & $100 \%$ \\
\hline Hispanic & $25 \%$ & $17 \%$ & $32 \%$ & $25 \%$ & $100 \%$ \\
\hline
\end{tabular}

Table 3: Proportional Distribution of Professional Staff in US ARL University Libraries by Race/ Ethnicity and Region, 2015

In analyses of previous ARL data sets, examining the age of racial and ethnic groups gave some hope that normal retirements might 
diversify the population. As an example, in $2000,48 \%$ of Caucasian professionals in US ARL university libraries were aged 50 and above, compared to just $35 \%$ of African Americans, and 39\% of Hispanics. Other factors being equal, the African American and Hispanic populations should have risen slightly in subsequent years as a result. By 2015, however, it was African Americans who were slightly older: 53\% aged 50 and above compared to $49 \%$ of Caucasians. "Normal retirements" in this context now constitutes another diversity challenge for ARL.

If the percentage of Caucasian professionals is inadequate as an indicator of the success of diversity efforts among ARL libraries, a better indicator can be found in the percentage of underrepresented groups among new hires. In 2015, we find halting progress: a slight improvement in African American recruitment, and fairly disappointing numbers of Asian and Hispanic new hires. The number of Caucasian new hires is almost identical to the portion of the larger ARL population, $85.5 \%$ compared to $85.1 \%$. (See Table 4.) The 2015 class of new hires can't be said to be diversifying the population.

\begin{tabular}{|l|r|r|r|}
\hline & \multicolumn{1}{|c|}{ N } & \% of professional staff & \% of new hires \\
\hline African American & 416 & $4.7 \%$ & $6.0 \%$ \\
\hline Hispanic & 259 & $2.9 \%$ & $2.1 \%$ \\
\hline Asian or Pacific Islander & 619 & $7.0 \%$ & $5.7 \%$ \\
\hline $\begin{array}{l}\text { Native American or } \\
\text { Native Alaskan }\end{array}$ & 35 & $0.4 \%$ & $0.7 \%$ \\
\hline Caucasian/Other & 7,576 & $85.1 \%$ & $85.5 \%$ \\
\hline
\end{tabular}

Table 4: Race/Ethnicity of Professional Staff in US ARL University Libraries, Overall and as a Portion New Hires, 2015

Diversity is of particular importance in leadership positions, and examination of positions with supervisory responsibilities yields 
disappointing results. As Table 5 demonstrates, the Caucasian portion exceeds that of the larger population.

\begin{tabular}{|l|r|r|r|r|r|}
\hline & $\begin{array}{c}\text { African } \\
\text { American }\end{array}$ & Hispanic & $\begin{array}{c}\text { Asian or } \\
\text { Pacific } \\
\text { Islander }\end{array}$ & $\begin{array}{c}\text { Native } \\
\text { American } \\
\text { or Native } \\
\text { Alaskan }\end{array}$ & $\begin{array}{c}\text { Caucasian/ } \\
\text { Other }\end{array}$ \\
\hline Director & $5 \%$ & $0 \%$ & $5 \%$ & $1 \%$ & $89 \%$ \\
\hline $\begin{array}{l}\text { Assistant/Associate } \\
\text { Director }\end{array}$ & $4 \%$ & $1 \%$ & $4 \%$ & $0 \%$ & $91 \%$ \\
\hline Head, Medical & $11 \%$ & $2 \%$ & $0 \%$ & $0 \%$ & $87 \%$ \\
\hline Head, Law & $5 \%$ & $3 \%$ & $2 \%$ & $2 \%$ & $89 \%$ \\
\hline Department heads & $4 \%$ & $2 \%$ & $6 \%$ & $0 \%$ & $87 \%$ \\
\hline
\end{tabular}

Table 5: Racial and Ethnic Groups as a Percentage of Supervisory Job Categories in US ARL University Libraries, 2015

\section{Female and Male ARL Professionals}

The ratio of female to male professionals in ARL university libraries has been as consistent over time as this population's racial and ethnic composition. ${ }^{5}$ Going back decades, women account for about $64 \%$ of the population. As with racial diversity,

There is at least one social upheaval...that has had a dramatic impact on the ARL professional workforce, and that is the trend towards women choosing to pursue, and being chosen for, leadership positions. this consistency is the more remarkable against the backdrop of social upheaval in this sphere. In the case of biological sex, the biggest demographic shift over the past 50 years has been the movement of young women away from traditionally female-dominated professions beginning in the 1960s and 1970s. ${ }^{6}$ In the case of librarianship, while younger women were not drawn to the profession, older women were, resulting in no discernable change in the ratio of females to males. Recent hiring trends seem unlikely to change things, as in 2015 , women accounted for $67 \%$ of new hires, just slightly higher than their share of the overall population. 
There is at least one social upheaval related to the ratio of female and male professionals that has had a dramatic impact on the ARL professional workforce, and that is the trend towards women choosing to pursue, and being chosen for, leadership positions. The case of ARL directors is the most visible, and arguably the most important. (See Figure 3.) The steady rise in the percentage of female directors is impressive between 1986 and 2005, the first year that females outnumber their male counterparts. Since 2005, that growth rate declines, such that in $2015,57 \%$ of directors were female.

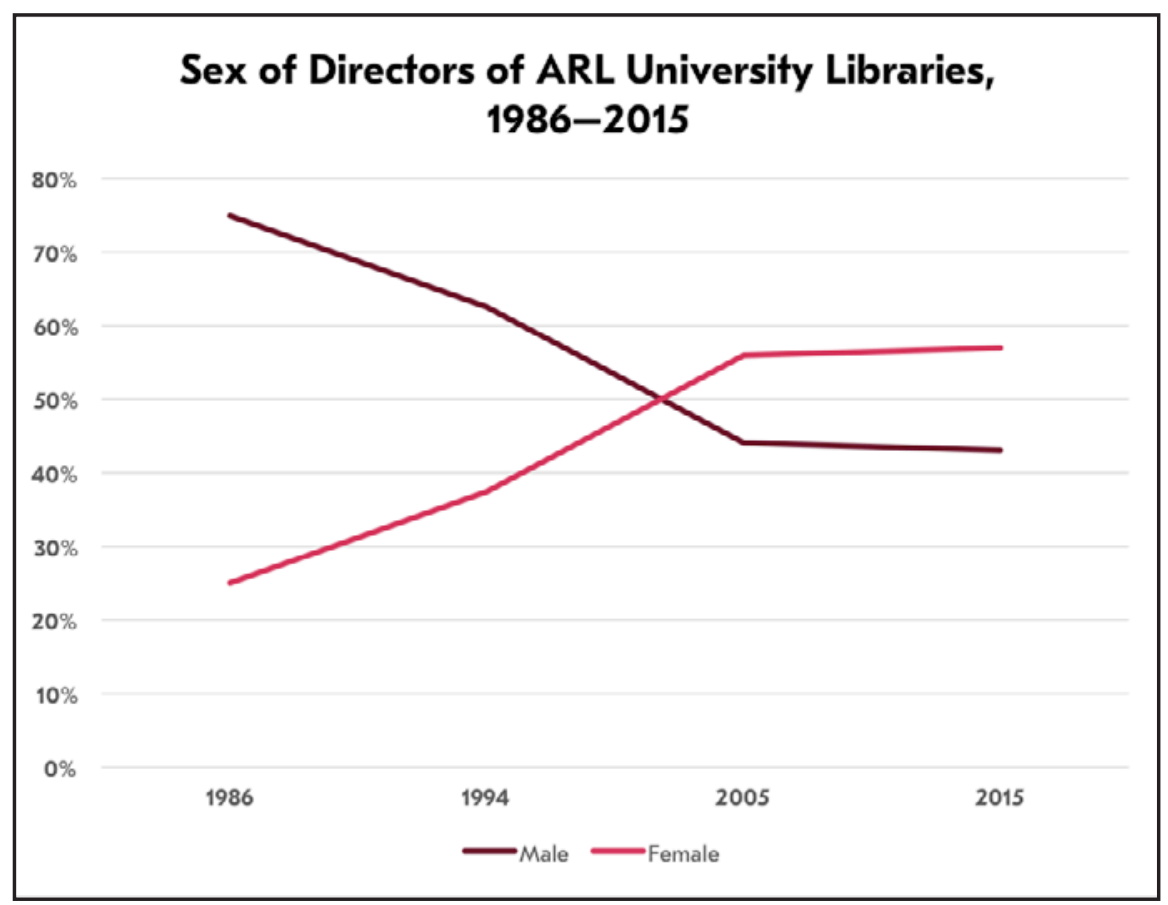

Figure 3

It is natural to expect the percentage of female directors to match their portion of the larger population, but there is no reason to think that it might not go higher still. ARL medical library directors are a case in point: interestingly, women held the majority of such positions going back to 1986, but began a steady rise in 1994, reaching 78\% in 2015. (See Figure 4.) By contrast, the graph of law library directors looks much closer to that of ARL directors, both groups having reached a tipping point around the years 2000 and 2005. (See Figure 5.) 


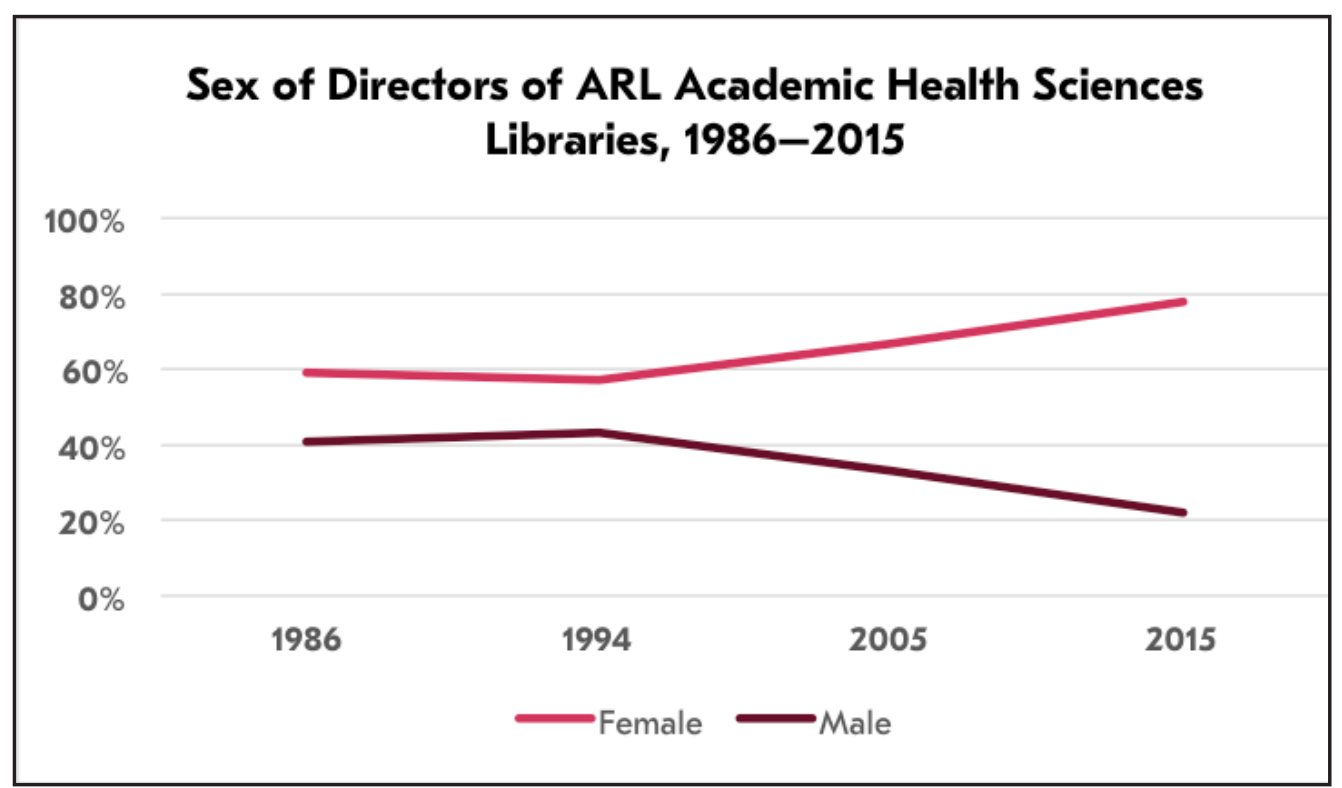

Figure 4

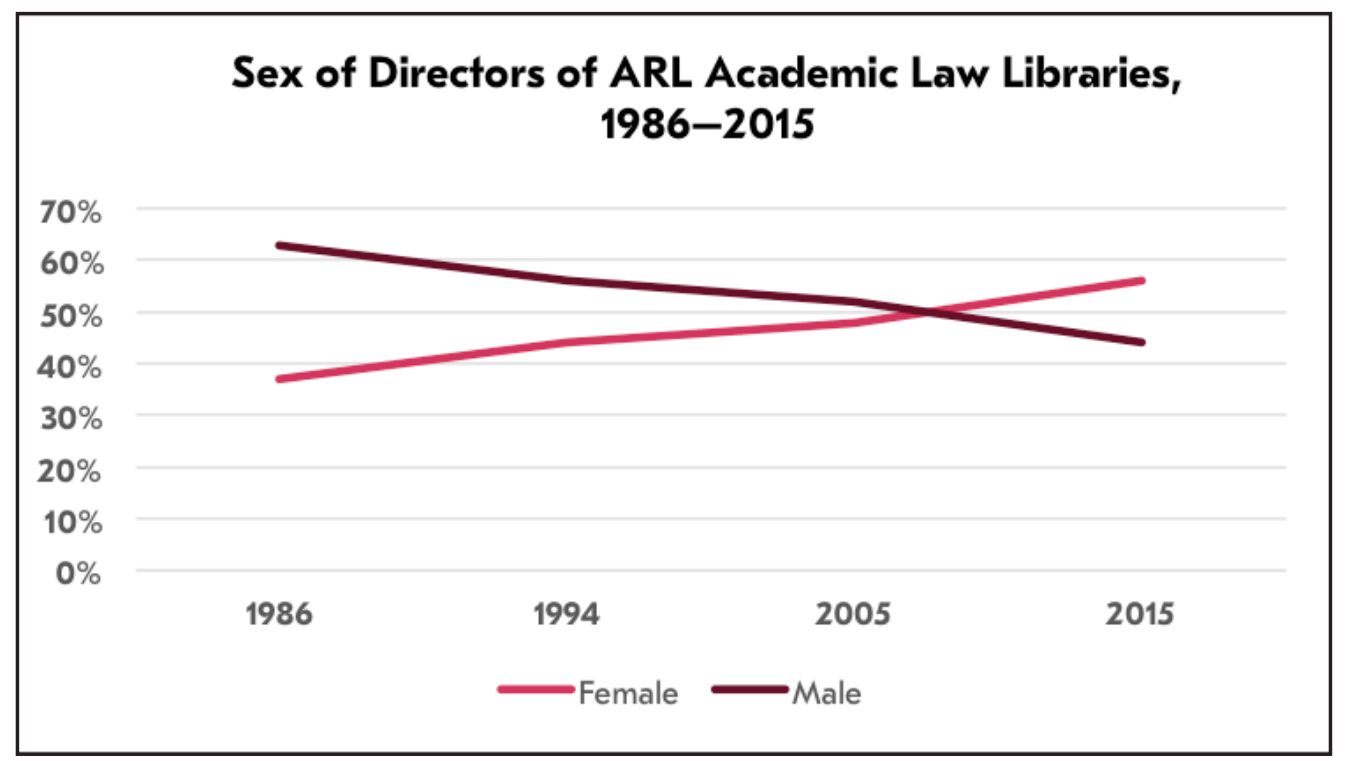

Figure 5

One reason the percentage of female ARL directors might go much higher is the numerical advantage that women held in 2015 in terms of associate and assistant dean (AD) positions, typically a springboard for director-level positions. (See Figure 6.) It must be said, however, that numerical superiority at the AD level did not seem to help women become directors in 1986. In any case, by 2015 the portion of male ADs had fallen to $37 \%$, the lowest number in the data series, and a level that approximates the overall ARL professional population. 


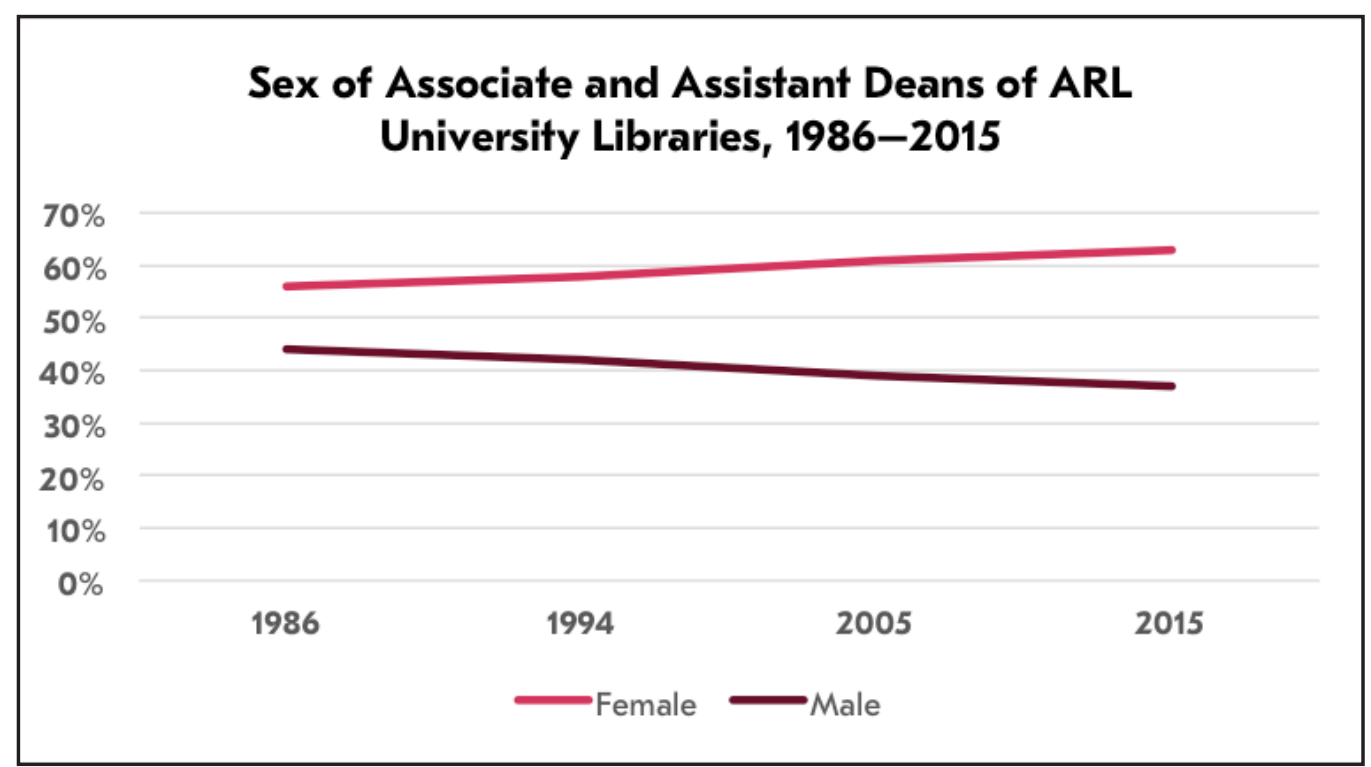

Figure 6

The distribution of females and males across department head positions has been remarkably stable dating back to 1986, mirroring the overall ARL population. (See Figure 7.)

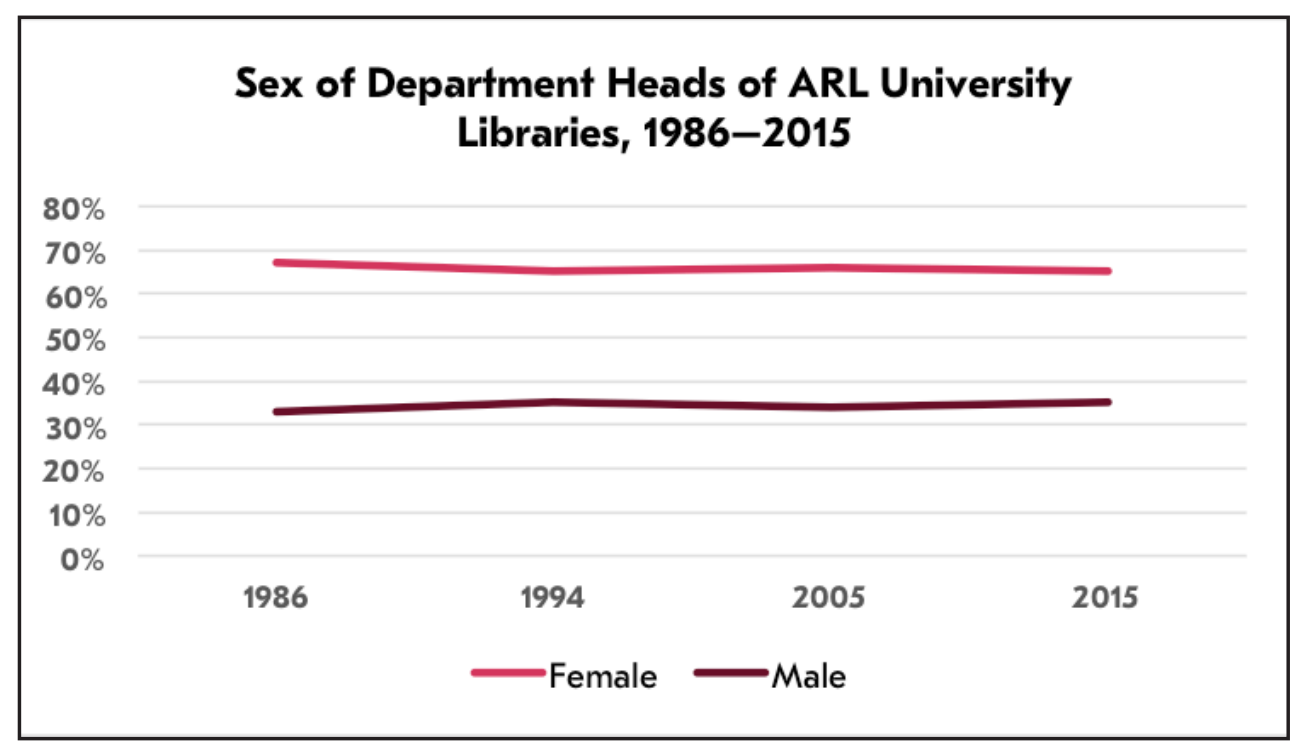

Figure 7

It is tempting to use this data set to examine female/male differences in compensation, but the data sets at my disposal are not capable of producing appropriately nuanced results. No matter, Quinn Galbraith's 2018 study covers the topic admirably, finding "relatively low pay gaps 
for women versus men."”

It is worth noting that Galbraith, along with Heather Kelley and Michael Groesbeck, published a similar article on the wage gap between Caucasian ARL professionals and those in historically underrepresented groups. Their analysis found that while wage gaps existed in the past, "there is no longer a statistically significant wage gap between racial minorities and nonminorities in ARL libraries today."

\section{Millennials}

By 2015, the oldest millennials had reached age 33, old enough to have a presence in the professional workforce. Millennials accounted for $12 \%$ of the ARL professional population in 2015, up from $2.4 \%$ just five years earlier, and in the time-honored way of generational change, their numbers are sure to grow for the foreseeable future. This process was already well under way when viewed from the perspective of new hires, $41 \%$ of whom were millennials in 2015 .

What do we know about millennials in the ARL population? These are early days for this cohort, but there is already one important emerging trend: millennials are much more likely to work in positions I have classified as "non-traditional." A "traditional" position is one for which the primary educational preparation can be traced to master of library science (MLS) degree program content, such as cataloging, reference, subject specialists, and public and technical services. "Non-traditional” jobs by contrast are those that draw principally on skills from other disciplines, such as functional specialists, the IT-based positions, and those that perform financial and human resource functions. The traditional/ non-traditional categories are thus rough

...we can be grateful for the emergence of a fresh generation that will see our current challenges with eyes uniquely qualified to adapt and then shape the next environment. The kids are alright. 
approximations, but they are useful in pulling together the emerging skill sets required by modern research libraries, skill sets that often benefit from strong demand beyond libraries.

Millennials are a case in point, insofar as $43 \%$ of them occupied nontraditional positions, compared to $32 \%$ of their older colleagues. It seems likely that a defining characteristic of millennial-age library professionals will be their grounding in work that may not have existed for previous generations. Millennials are a revolution in the making.

Except when they are perfectly ordinary. In many of the ARL demographic variables, the 2015 millennials aren't noticeably different from their colleagues in terms of the distribution of females and males, underrepresented racial and ethnic groups, or credentials. Millennials are underrepresented in leadership positions, but no more so than their youthful counterparts in previous years. If millennials are going to change the culture, values, and product of research librarianship, it is not at all clear what that change will look like.

But of course millennials will change all those things, just as every generation before them did. The cognitive scientist Alison Gopnik addresses this phenomenon when discussing how the minds of children are wired to think the world afresh, and the principle of biologically driven generational change applies in any context. The writer Michael Pollan quotes Gopnik speaking on this point in his book How to Change Your Mind:

Each generation of children confronts a new environment...and their brains are particularly good at learning and thriving in that environment. Think of the children of immigrants, or four-year-olds confronted with an iPhone. Children don't invent these new tools, they don't create the new environment, but in every generation they build the kind of brain that can best thrive in it. ${ }^{9}$

Coming to understand the kinds of brains that our millennial-aged 
professional colleagues are building feels like a compelling, even urgent question, but we will not get there with demographic data such as ARL collects. The problem here isn't that the ARL data doesn't ask enough questions, or even the right ones. It is instead a reflection of the limitations of demographic research, and maybe quantitative research altogether. The impact of millennials on culture, values, and product are better suited to qualitative research methods. In the meantime, we can be grateful for the emergence of a fresh generation that will see our current challenges with eyes uniquely qualified to adapt and then shape the next environment. The kids are alright.

\section{Endnotes}

1 The meaning of "professional" is self-defined by each library that responds to the ARL Annual Salary Survey.

2 Martha Kyrillidou and Shaneka Morris, comps. and eds., ARL Annual Salary Survey 2014-2015 (Washington, DC: Association of Research Libraries, 2015), 25, https://doi.org/10.29242/salary.2014-2015.

3 Canadian ARL libraries and non-university ARL libraries do not report data on racial/ethnic group status.

4 Campbell Gibson and Kay Jung, "Historical Census Statistics on Population Totals by Race, 1790 to 1990, and by Hispanic Origin, 1970 to 1990, for the United States, Regions, Divisions, and States," Working Paper no. 56, Washington, DC: US Census Bureau, Population Division, September 2002, 154-162 (164-172 in PDF), Table F-1: Race and Hispanic Origin, for the United States and Historical Sections and Subsections of the United States: 1790 to 1990, https://census.gov/content/dam/ Census/library/working-papers/2002/demo/POP-twps0056.pdf.

5 Currently, the ARL Salary Survey collects data on the distribution of male and female professional-level employees in ARL university libraries, in keeping with the sex categories utilized by the US Census. Although this allows ARL Salary Survey data to be compared with state, local, and national labor statistics, the Association realizes the limitations 
of this approach and acknowledges the distinct and important ways that gender identity, sexual orientation identity, and biological sex intersect and contribute to each person's unique way of experiencing the world and the workforce. ARL is committed to diversity, equity, and inclusion as guiding principles of the organization and recognizes and embraces the full spectrum of human and social identities, including, but not limited to, race, ethnicity, national origin, gender and gender identity and expression, sexuality, ability, veteran status, class, and religion.

6 Stanley J. Wilder, Demographic Change in Academic Librarianship (Washington, DC: Association of Research Libraries, 2003), 16.

7 Quinn Galbraith, “The Effect of Gender and Minority Status on Salary in Private and Public ARL Libraries," Journal of Academic Librarianship 44, no. 1 (January 2018): 75-80, https://doi.org/10.1016/j. acalib.2017.10.005.

8 Quinn Galbraith, Heather Kelley, Michael Groesbeck, "Is There a Racial Wage Gap in Research Libraries? An Analysis of ARL Libraries," College and Research Libraries 79, no. 7 (November 2018): 863-875, https://doi.org/10.5860/crl.79.7.863.

9 Michael Pollan, How to Change Your Mind: What the New Science of Psychedelics Teaches Us about Consciousness, Dying, Addiction, Depression, and Transcendence (New York: Penguin, 2018), 327.

(C) 2018 Stanley Wilder

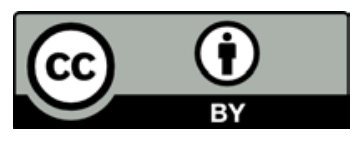

This article is licensed under a Creative Commons Attribution 4.0 International License. To view a copy of this license, visit https:// creativecommons.org/licenses/by/4.0/.

To cite this article: Stanley Wilder. "Selected Demographic Trends in the ARL Professional Population." Research Library Issues, no. 295 (2018): 32-45. https://doi.org/10.29242/rli.295.4. 


\section{/ ASSOCIATION \\ LIBRARIES}

\section{Research Library Issues}

Research Library Issues (RLI) focuses on current and emerging topics that are strategically important to research libraries. The articles explore issues, share information, pose critical questions, and provide examples. Suggestions for potential themes, articles, and authors are welcome. Please submit suggestions via this online form.

ISSN 1947-4911 https://doi.org/10.29242/rli

Executive director: Mary Lee Kennedy

Editor-in-chief: M. Sue Baughman

Managing editor: Kaylyn Groves

(c) 2018 Association of Research Libraries

ARL policy is to grant blanket permission to reprint as long as full attribution is made. Exceptions to this policy may be noted for certain articles. This is in addition to the rights provided under sections 107 and 108 of the Copyright Act. For more information, contact ARL Publications, pubs@arl.org.

Current and back issues are available on the ARL Digital Publications website, publications.arl.org/rli. The website is also where you may sign up for alerts to new releases of Research Library Issues.

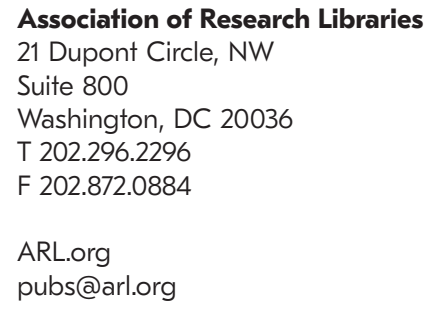

T 202.296.2296

F 202.872.0884

ARL.org

pubs@arl.org 